Portland State University

PDXScholar

1976

\title{
A Validity Study of Select Symbol-Referent Relationships Using Semantic Differential Ratings
}

Stephen Willard

Portland State University

Follow this and additional works at: https://pdxscholar.library.pdx.edu/open_access_etds

Part of the Cognitive Psychology Commons

Let us know how access to this document benefits you.

\section{Recommended Citation}

Willard, Stephen, "A Validity Study of Select Symbol-Referent Relationships Using Semantic Differential Ratings" (1976). Dissertations and Theses. Paper 2592.

https://doi.org/10.15760/etd.2589

This Thesis is brought to you for free and open access. It has been accepted for inclusion in Dissertations and Theses by an authorized administrator of PDXScholar. Please contact us if we can make this document more accessible: pdxscholar@pdx.edu. 
AN ABSTRACT OF THE THESIS OF Stephen Willard for the Master of Science in Psychology presented June 3, 1976.

Title: A Validity Study of Select Symbol-Referent Relationships Using Semantic Differential Ratings.

APPROVED BY MEMBERS OF THE THESIS COMMITTEE:
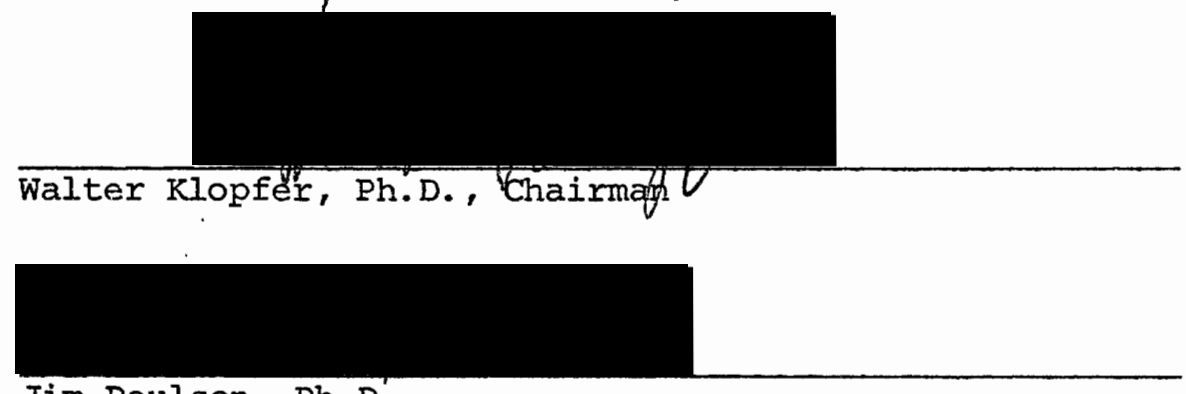
Jim Paulson, Ph.D.

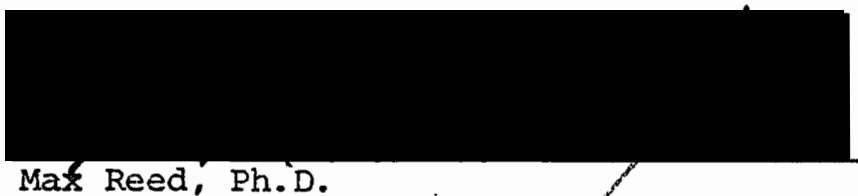

The present research was conducted in order to develop a method useful for measuring the meaning of symbolic material. Using this . method an investigation was conducted to test the validity of several personality theories which ascribe meanings to select symbols.

A summary of the major personality theories dealing with symbolic material was conducted. Each theory was briefly presentad with a discussion of the methods employed to determine the meanings of symbols. A set of symbol theory considerations was presented which would suggest the necessary components of an objective investigation attempting to be a validity test of symbol meanings predictions.

A review of validation studies of symbolic material revealed 
numerous methodological errors. A number of investigations gathered denotative meanings data, which is deemed inappropriate for testing symbols. Other investigations employed data methods which generated connotative meanings data, but made apparent methodological errors in their data analysis. Free association data studies only included "significant" results from half of the respondents. Semantic differential data investigations included neutral meanings and non-significant meanings in making meanings, determinations.

Two highly quantified clinical investigations of intrapersonal symbol systems were reviewed. The case studies presented were few in number and did not include symbol's predicted by personality theorists. The semantic differential technique coupled with a data analysis procedure that preserved individuals symbol-referent relationships was used to investigate the meaning of ten symbols and six theoretical referents. Data from the ratings of twenty male and twenty female Ss was used to test the validity of the symbol-referent relationships predicted by specific theorists.

Results of the study suggested that on a cultural level the following symbol-referent relationships were validated: WIZARD, SWORD and ELEPHANT as FATHER symbols. ASCENT as a symbol for CONSCIOUS. VASE as a MOTHER symbol. HOUSE was a ME symbol for both sexes as was SWORD for male Ss and VASE for female Ss.

Results of the investigation supported the following universal symbol-referent relationships for individuals: ASCENT as a symbol for CONSCIOUS. VASE as a MOTHER symbol for both sexes and a ME symbol for female Ss. WIZARD, SWORD and ELEPHANT as FATHER symbols and SWORD 
as a ME symbol for male $\underline{S}$. HOUSE was a ME syiabs at both sexes.

Symbol-referent relationships not. validatce ind ied cow and WITCH as MOTHER symbols. Symbol-referent relatiditid not validated because of nonsignificant meanings included DESCH. VINCONSCIOUS and DRAGON for PROHIBITIONS.

Female Ss did not validate the predicted syron wor masculine or feminine symbols as much at the ingivi riplationships data level as at the cultural level. Male Ss whisidy validated both masculine and feminine symbolism predictions at $x+31$ cultural and individual relationships levels.

Male Ss may employ stereotyped meanings more that: do female Ss or may actually use the symbols. Female Ss may not eny the symbols yet may be aware of their meanings at a cultur ? $?$ rise predominant support of the males for predictions may be iritusive ct a male orientation of personality theorists in viewing syabolss rather than universal symbolism.

The method employed for validating symbol-refecent relationships is believed to be useful to clinicians to differentiats yersonal, cultural and universal components of symbol meaning. 
A VALIDITY STUDY OF SELECT SYMBOL-REFERENT

RELATIONSHIPS USING SEMANTIC

DIFFERENTIAL RATINGS

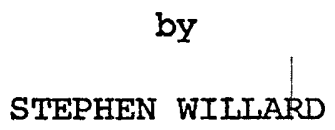

A thesis submitted in partial fulfillment of the requirements for the degree of

\title{
MASTERS OF SCIENCE \\ in \\ PSYCHOLOGY
}

\author{
Portland State University \\ 1976
}


TO THE OFFICE OF GRADUATE STUDIES AND RESEARCH:

The members of the Committee approve the thesis of

Stephen Willard presented June 3, 1976.
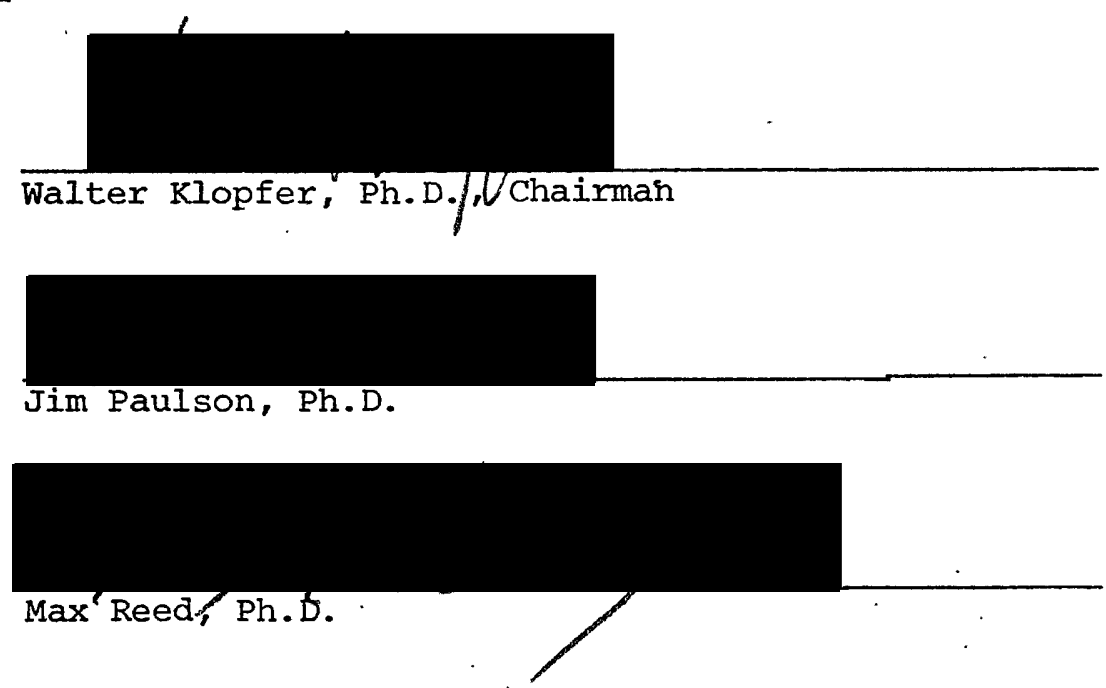

APPROVED:

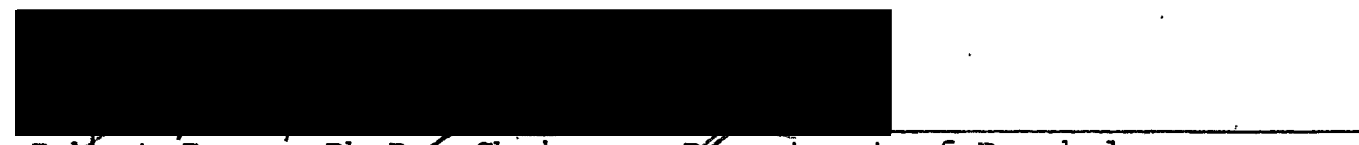

Robert Jones, Ph.Df, Chairman, Department of Psychology

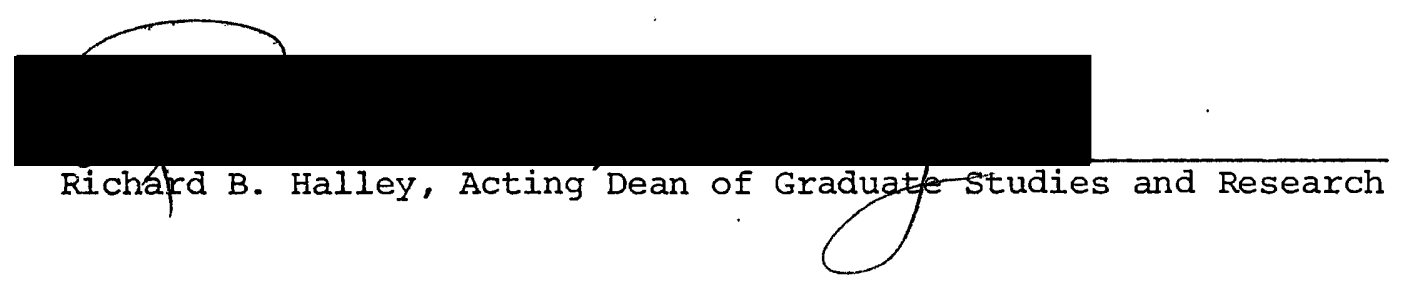


TABLE OF CONTENTS

PAGE

LIST

TABIES

iv

CHAPTER

I INTRODUCTION . . . . . . . . . . . . . . I

II REVIEW OF THE IITERATURE . . . . . . . . . . . . 4

Personality Theorists Investigation of

Dream Symbols .............. . . 4

Objective Investigations of Symbols . . . . . 8

Association Studies . . . . . . . . . 12

Semantic Differential Investigations . . . . . 15

III RESEARCH DESIGN . . . . . . . . . . . . . 21

IV RESEARCH METHOD . . . . . . . . . . . . . 26

Stimulus Concepts and Semantic Differential

Scales.............. . . 26

Subjects and Administration Procedures . . . . 28

Data Analysis Procedures.. . . . . . . . 29

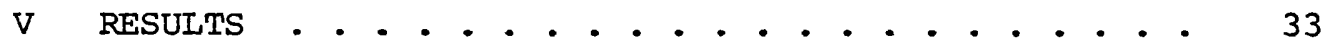

Significance of Ratings and Popular Connotations . . 33

Normative or Popular Symbol-Referent Relationships . . . . . . . . . . 39

Idiosyncratic Symbol-Referent Relationships . . 42

VI DISCUSSION . . . . . . . . . . . . . . 47

BIBLIOGRAPHY . . . . . . . . . . . . . . . 55

APPENDIX . . . . . . . . . . . . . . . . . 59 


\section{IIST OF TABLES}

I Mean Ratings of Concepts for Male and Female Ss . . 34

II Summary of Significant Scales and Concepts

by Sexes ............... . . 35

III Quantifiexs Corresponding to Each Scale Unit . . . . 37

IV Normative or Popular Rankings for Hypothesized

Symbol-Referent Comparisons ......... . 41

$\checkmark$ Average of Individuals' Symbol-Referent

Relationships for Hypothesized Comparisons . . . 44

VI Contrasted Comparisons Using Individuals' Symboi-

Referent Relationships Average Rankings . . . . 46

VII Popular Connotations of Symbols and Referents

for Male and Female Ss . . . . . . . . 60

VIII Populax or Normative $D^{2}$ Between Symbols

and Referents for Male Ss . . . . . . . 63

IX. Popular or Normative $\mathrm{D}^{2}$ Between Symbols and

Referents for Male Ss... . . . . . . 64

$\mathrm{x}$ Popular or Normative $\mathrm{D}^{2}$ Between Symbols and

Referents for Female Ss . . . . . . . . 65

XI Popular or Normative $\mathrm{D}^{2}$ Between Symbols and

Referents for Female Ss ... . . . . . . 66 
XII Popular or Normative $\mathrm{D}^{2}$ Between Symbols and

Referents for Female and Male Ss . . . . . 67

XIII Popular or Normative $\mathrm{D}^{2}$ Between Symbols and Referents

for Male and Female $\mathrm{SS}:$.......... 68

XIV Average of Individuals $\mathrm{D}^{2}$ Relationships Between Symbols and Referents for Male $\mathrm{Ss}$. . .........69

$\mathrm{XV}$ Average of Individuals $\mathrm{D}^{2}$ Relationships Between

Symbols arả Referents for Male Ss . . . . . . 70

XVI A. Average of Individuals $\mathrm{D}^{2}$ Relationships Between

Symbols and Referents for Female Ss . . . . . 71

XVII Average of Individuals $\mathrm{D}^{2}$ Relationships Beiween

Symbols and Referents for Female Ss . . . . . 72

XVIII Average of Individuals $\mathrm{D}^{2}$ Relationships Between

Symbols and Referents for the Combined Sample . . 73

XIX Average of Individuals $\mathrm{D}^{2}$ Relationships Between.

Symbols and Referents for the Combined Sample . . 74 
CHAPTER I

INTRODUCTION

Freud, Rorschach, Jung and other personality theorists developed elaborate theoretical systems to explain the dynamics operating in symbol formation. These clinicians developed techniques for tapping unconscious processes which made possible symbol meaning determinations for themselves and their patients. As these major personality theorists worked with symbols they postulated meanings often associated with specific symbols. Freud, Jung and the others often predicted universal principles of symbol meanings that would hold for most people experiencing a specific symbol. The predictions about specific symbols meanings were used by other clinicians to determine meanings of their patients symbols.

Numerous research studies were conducted in attempts at testing the validity of the specific symbol meanings predictions made by the major personality theorists. The results of these investigations were interpreted as supporting or not supporting the specific symbol predictions and further used to validate or call into question the basic theoretical dynamics of a particular personality theory.

In reviewing the many studies that were designed to test the validity of symbol meanings predictions numerous methodological errors and constraints were discovered which weaken many studies and virtually invalidate some studies. Errors were of two basic types, first errors 
of study design and, second, exrors in methodology of data analysis.

Many objective research strategies for measuring symbol material did not employ data collection procedures or tap appropriate levels of meaning so as to be able to test the symbols meanings as predicted by the theories. These studies lacked construct validity when compared to the theories they were attempting to test. Other researchers utilized techniques which collected meanings data from unconscious or affective levels, yet when analyzing the data chose to disregard much of the data or did not use appropriate analysis procedures. Results and conclusions from these studies were based upon incomplete, neutral meanings or non-significant meanings data.

This research was conducted in order to determine a method useful for measuring the meaning of symbolic material.

Using this appropriate method, an investigation was conducted to test the validity of some of the symbol-referent connections predicted by personality theorists.

The review of personality theorists clinical empirical investigations of symbol material will provide the framework from which the hypothesized symbol meanings to be tested were developed. The theoretical constructs and methods employed by these theorists to determine the meaning of symbols will be described to assure that the validation method developed is germane to the theories to be tested. To develop appropriate techniques and procedures for measuring symbolic material, a critical methodological review of other investigations of symbolic and projective materials will be made.

The method for symbol meaning measurement developed will be used 
to provide data to test the validity of specific symbol-referent relationships. By including both referents and symbols hypothesized by the personality theorist to have the same meaning as the referent on the unconscious, connotative or feeling tone levels, it will be possible to directly test the validity of hypothesized symbol referent relationships.

The finding will be discussed in terms of components of symbolism addressed by symbol theories, including universal, cultural and idiosyncratic aspects of symbol meaning. 
CHAPTER II

REVIEW OF THE IJITERATURE

\section{Personality Theorists Investigations of Drear Symbols}

Freud, Jung and other clinicians investigating dream symbolism developed numerous techniques for gathering material relevant to dream interpretation. They developed theories describing certain dynamics operating in dream symbolism. Each theorist used his techniques for tapping unconscious processes to gather empirical data which often only supported the theory he had developed. The proof for a symbol theory was found in examples draw from patients in the clinicians practice.

Freud's (1952, 1953, 1.960) theory of dream interpretation was built upon several interlocking tenets. He believed the process of dream formation was an unconscious one in which the dream was a compromise between unexpressed sexual or hostile impulses and the resistance of moral attitudes (censorship). Ego alien impulses were transformed or disguised through symbolism by the processes of dxamatization, condensation, displacement ard secondary elaborations.

A symbol was defined as sunething that stood for, represented or denoted something else. Dream interpretation involved developing an understanding of the iatent content (repressed content) through exploration of the drean report's symbolized contents (manifest content) by use of the free association technique. Freud believed that symbols 
which express unconscious material were often determined by physiognomic resemblances. These "true symbols" were universal or constant in meaning. Within the Freudian framework, dream interpretation involved analysis of the manifest dream reports by making structural and functional comparisons between dream symbols and the male and female genital organ symbolized (latent content) (Bartlett, 1932). Freudian theory would predict that the symbol SWORD was a symbol of the male penis by virtue of its structural similarity to the referent. Likewise the symbol VASE would be a feminine vaginal symbol because of its properties of concavity, holdingness and curvature. Proponents of psychoanalytic theory have utilized these interpretative formulations in their practices and writings. Bartlett (1932) and Jones (1948) report the validity of the sexual shape interpretations and offer clinical case evidence for support.

Carl Jung $(1957,1964,1970)$ developed theoretical hypotheses which emphasized the purposeful structure and functions of dream symbols. He believed dreams expressed specific unconscious wisdom of a transcendental nature. Dream interpretation was accomplished through understanding the dream contents (dream symbols) by relating them to mythological symbol motifs. Through use of the amplification method, associations of a symbol to many symbol motifs, it was possible to determine both universal and individual meanings of the symbol. The symbol WIZARD would often represent a father symbol as born out by the universality of the wise old men archetype. The symbol WITCH would often carry the meanings associated with the negative aspects of the dreamer's mother. Jungian theory stressed the need for coupling universal (archetypical) 
symbol meanings with personal symbols meanings, resulting from each patients individual meanings, experiences, when arriving at a full meaning of the dream symbol. Universal or constant meanings were not attributed to symbols. Dream symbol interpretation was a process whereby the patient related his symbols to archetypical symbol motifs, his personal meanings, and the therapists intuitive clinical interpretative hypotheses.

Roberto DeSoille (1965) noted that spontaneous visual imagery of his clients centered around several symbol motifs and that certain symbol images had associated with them affectual responses that were the same for most people he worked with. He developed a symbolic projective therapeutic technique which he called the Reve Eveille dirige or directed daydream.

The directed daydream images had components that described symbolically the patients relationships with others, his emotional responses toward them, and his feelings toward events in his life. DeSoille developed a framework for interpretation of symbols built upon Jung's (1957) idea of archetypical motifs, used in dreams and fantasy, as expression vehicles for statements of significant life relationships and events of the patient. Desoille found that the fantasy of ascent was associated and equivalent in meaning to consciousness and that the imagination of descent had meaning equivalent to the person's feelings about the unconscious. Van Den Berg (1962), who used the Directed Daydream Technique, presented clinical cases in support of Desoille's (1965) hypotheses of symbol motif meanings. Hanscarl Leuner (1969, Swartley, 1965a) developed a symbol 
interpretation technique (Initiated Synbol Projection) also based upon waking symbol productions. Interpretation of symbols was possible through a regression hypothesis, in which childhood perceptions formed the basis for the symbol meanings. Leuner believed that pre-language symbols of the child functioned in most symbols created by adults. His clinical studies validate various symbols used in the initiated symbol projection technique. Leuner found cow often to be a mother symbol and ELEPHANT to be a father symbol.

The Personality Theorists collected symbol meaning information through a variety of techniques (free association, amplification, forced fantasy, directed daydream, initiated symbol projection) from patients in therapy. Using these techniques as a means of generating information which seemed to reveal symbol meaning on small select patient populations as well as with themselves, these clinicians developed comprehensive theories of symbol.interpretation and proposed their numerous methods as the means for generating data relevant to symbol meaning determination. Although their fundings were clinicalempirical, these investigators were not operating without theory bias. Subjective interpretations could influence their data objectivity in observation, recording and interpretation. Since most of the population from which the symbol data was drawn was a patient population, subtle interactions between the therapist, and patient, consciously or unconsciously may have contributed to self-fulfilling prophecies regarding symbol meanings.

Early clinicians often worked from a theory which provided a comprehensive a priori framework for analysis of symbol meaning. This a priori framework may have forced symbols into meanings that did not 
fit the dreamers symbol meaning, but fit the therapists way of understanding or his criterion for "acceptance of meaningful material" in the analysis. These theories of dream symbol meanings yielded conflicting determinations of symbolization. Conflicts of symbol determination from various theories, coupled with the subjective non-concise methods employed for describing symbolization leaves no systematic approach for establishing refutation or validity of theoretical symbolization meaning systems. The conflicts in interpretation at best point to the limited applicability of the theories and call to question the validity of meanings interpretation as claimed by their statements of universality. The need for objective studies of symbol meaning was necessary to provide data useful for validating, the symbol theory predictions and the symbol theory systems.

Objective Investigations of Symbols

Objective research in the area of symbols has been lacking in several areas vital to the objectification necessary for validating symbol theory formulations. Methodological approaches designed to test symbol theory predictions failed to include data collection and analysis procedures that would adequately test the theory, thus the research strategy was not congruent with formulations of the symbol theory. In many of the research procedures investigators failed to consider the nomothetic-idiographic data collection problem. They used average data to validate individuals symbol use and often included personal meanings data into the "error factor". Other researchers have included methodological errors of various kinds in their data analysis methods. Symbol theory is based upon several hypotheses relevant to the 
process involved in symbolization. It is known that symbols are transformed along denotative dimensions. Thus a dream symbol for the penis is denotatively (descriptively, directly) altered becoming a symbol "necktie" (sword, baseball bat, etc). The connotative aspects (feeling tone, emotional meaning, suggested meaning) remain constant and represent the same class of meaning responses associated with penis. This transformation is thought to be made in the unconscious since the conscious is often unable to attribute meanings to the symbols of dreams. The fact that many investigators of symbol meaning did not collect data from unconscious levels, invalidates their investigations as tests of symbol theory predictions.

Symbol theories as formulated by Freud (1952, 1953, 1960), Jung (1957, 1964) and other clinicians included procedural techniques for differentiating multiple components of symbol meanings. Symbols were seen to have meanings determined through universal components (universal sexual symbolism, archetypes), cultural components (community usage, mythical usage), personal components (trauma fixations, personal meanings), and contextual components (use in dream context, dream themes). In practice symbol meanings were ascribed only after combining the patient's associations to dream symbols and the universal meanings. For Freud, a symbol meaning could only be understood within the patient's understanding of the personal meanings, the cultural sex role expectations and the universal sexual usage hypotheses. Bartlett (1933) stated that a symbol can only be interpreted in "reference to the mental life and personal history of the individual who uses it, or to the social life and the history of the group that employe it." Jung (1957) emphasized 
the need for interpreting symbols through archetypical (universal) symbol motif, through the amplifications of the personal history-meaning of the person experiencing the symbol and contextual meanings assigned to the symbol in the dream theme or the series of dreams patterns. Fromm (1951) used a dream symbol interpretation procedure that drew upon universal, socio-cultural, and personal associations as well as uses of the symbol, before ascribing meaning. W. G. Klopfer (1954) described the process necessary for determining the meaning of symbolic Rorschach contents. He emphasized the need for symbolic determination to be based upon inter-related hypotheses, structural hypotheses, hypotheses from other tests and case history máterial, and a testing-the-limits association method. He warned of making the assumption that the individual was attributing stereotyped characteristics to the symbol he was perceiving.

These procedural techniques allowed the clinician to gather data tapping all dimensions of the patient's meanings associated with the symbol and were in keeping with symbol theories. Objective investigations of symbol meanings failed to gather this type of data or failed to preserve personal meanings when analyzing their findings:

One major problem faced by researchers attempting to objectively test the meanings of symbols was development of a method of data collection and analysis that would tap appropriate aspects of symbol meaning. Most investigations conducted in attempts to test Freudian predictions about the sexual shapes of line drawing used variations on denotative (direct, conscious, obvious) data. Techniques employed included matching shapes (Iine figures) with male or female names, 
(Levey, 1954; Stinnett and Thurlow, 1958; Acord, 1961, 1962) with sex roles (Lessler, 1962, 1964), or chosen as a male or female character in a story (Barker, 1957).

Data from most of these investigations supported the universal sexual symbolism hypothesis of Freud for both adult normal and psychotic populations (Acord, 1961; Jones, 1956; Lessler, 1962, 1964; Starrer, 1955; Stinnett \& Thurlow, 1958; Winter \& Prescott, 1957). Data for pre-adolescent populations was mixed. Levey (1954) and Acord's (1962) data not supporting while Jones (1961) and Lessler (1962) found support. Those investigators who found strong support for Freudian predictions used denotative data which is least able to demonstrate the meaning. of the symbol. The denotative dimension is the one through which symbols are transformed(i.e., penis, as a referent, is transformed into sword, a symbol) while the connotative dimension is the one maintaining meanings equivalencies (i.e., penis with its affective meanings of masculinity and self-concept for males equals sword, which if used as a symbol, will have the same affective meanings of masculinity and self-concept for males.) The use of denotative measures may lead the

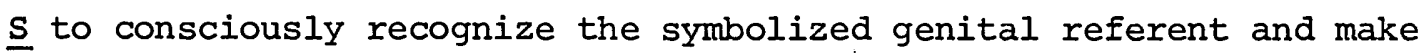
a defended response. The defended response data may be consonant with psychoanalytic predictions, or elicit a denial that there is a meaning to the symbol. Freudian symbol theory would predict the above possible modes of responding making data from studies using only denotative measure unable to "test" the theory.

Further, the nomothetic assumptions used in these data procedures which tabulate only theory "correct" responses included in the "error 
terms" responses that may have supported the theory being tested. A female $\underline{S}$ with a masculine self-concept might include symbols psychoanalytic theory would predict a masculine in the female classification. This would provide support for Freudian theory, but constitute objective data for refutation within the normative study.

\section{Association studies}

While not falling into the dilemma of using denotative data to measure symbol meanings, the many investigations which employed free association techniques encountered difficulty in summarizing their results. The nomothetic assumptions required to quantitatively describe the data made conclusions from the studies not useful for validating incividuals usage of symbols.

The free association technique, which Freud (1952) had demonstrated as most useful for bringing unconscious material into consciousness, tapped directly the dimension at which symbol meanings were carried (the connotative, unconscious, feeling tone, affectual or latent). This technique was employed to test the meanings of responses given to Rorschach contents (Earl, 1941) to determine the meaning of animal symbols and their relationship to family members (Goldfarb, 1945, Buss and Durkee, 1957) and to test the sex role of animal symbols (Gill, 1967). Both Earl and Goldfarb concluded that there were no universal meanings and that specific symbolism could be attached to any Rorschach response or animal symbol. Goldfarb found that no animal had the same meaning for all the $\underline{S}$, and that for the $\underline{s}$, a specific animal symbol may have different meanings at different times. He described dimensions of symbolism that seemed to exist for some Ss! Adults were associated with 
large animals, cruel adults with aggressive animals, and kind adults with domestic animals. Man was associated with gorilla; cow with woman, and bearcub and fish with babies.

Buss and Durkee (1957) used the free associations of animals to familial figures and familial figures to animals with large adults samples and found no single animal associated to any familial figure. They did find support for dimensions of animal-familial symbolization. They concluded size and aggressive dimensions did indicate some cultural stereotypity of animal symbol usage for adults. Loving mother was symbolized by cow, deer, chicken, bird, cat, rabbit, and dominating father associated with bull.

Buss and Durkee (1957) described the problems involved in using association as a technique for generating data showing the symbolic relationships between animals and familial figures. The associations of the first $10 \underline{\mathrm{Ss}}$ to "timid father" were: Ilama, bird, monkey, fox, lamb, ram, bird, horse and rabbit. This variability of associations to familial figures forced them to adopt a strategy of describing the dimensions of animals (large-small, domestic-wild) which seemed to hold for the associations of at least $50 \%$ of the Ss to any familial figure. Data for the remaining $50 \%$ of the Ss which could not be described with this dimension was lost.

In Gill's (1967) study of the associations of adults and adolescents to animals, he found that of the 50 symbolized relationships developed in personality literature, only five had stereotypity of sex role meaning across age and sex groups. Dimensions of meaning were found to correspond to sex role animal designations (e.g., passiveactive with female-male). A consistency was found between animal 
associations and animal responses given to the Rorschachs by the same s. Finding only 5 of the 50 sex symbol relationships described in the literature confirmed, Gill (1967) called to question the psychoanalytic predictions of universal sex roles for certain animal symbols. Gill was able to include groups of associations to animals for Ss responding with appropriate psychoanalytic predictions designations of sex roles as well as for the $\underline{S}$ who did not assign the stereotyped sexual gender to the animals. He found that those who deviated from the average in assigning sex role showed a predominance of negative feelings toward both sexes. With these sub-group averages, he was able to more adequately describe the data, but was unable to conclude if meaningful personal aspects of symbol usage were being described.

Association methods are unable to describe their objective data in a manner so as to provide information relevant to individual usage of symbols and often are forced to disregard as much as $50 \%$ of "discrepant" data when summarizing their data.

Rychlak (1959) used a forced association design to circumvent. the problem found in the free association studies. He had adult Ss rate Rorschach constructs (fire, mask, clouds, etc.) with a series of six descriptive adjectives or meanings (positive meaning, negative meaning, Iove, security, anger, depression) often assigned to these constructs by clinicians. He found that many commonly held interpretations of the constructs (symbols) were supported. Rychlak interpreted the data as providing support for a cultural symbolism hypothesis, and suggested this resulted because patients were in the same sociocultural field and had available the same pool of symbols. Iimiting the response options of the $\underline{S}$ to only six choices greatly restricted 
the scope of this study. The most highly refined method used for detexmining quantitative measure of meaning, while allowing a broad range. of choices, was the Semantic Differential.

\section{Semantic Differential Investigations}

Iike the free association methods, the Semantic Differential also taps the appropriate level of meaning for measuring symbolic materials. The Semantic Differentiai as developed by Osgood (1957) provides a direct method for quantifying affective, feeling tone, or connotative aspects of meaning. This technique has an advantage over free association methouss in that it limits the range of content response options while allowing ample opportunity for Ss expression of magnitude and direction of comnotative meanings responses. Results from the Semantic Differential investigations fails to validate universal meanings predictions for sexual shapes (Schonbar and Davitz, 1960); stereotyped universal meanings for animal symbols (Goldfried, 1953 and Goldfried and Kissel, 1963); the stereotyped meanings of popular Rorschach percepts and personal concepts (Pope and Bare, 1961); and yields mixed results in investigations of Freudian and Jurgian universal sexual Noun symbols (Worthy and Craddick, 1969, Archer and Burgess, 1970, Craddock and Worthy, 1970 and Althouse, 1970). The Semantic Differential was also used to measure a few individuals idiosyncratic symbol systems (Osgood and Iauria, 1954 and Moss, 1970).

The conclusions derived from the studies of Schonbax and Davitz, Goldfried, and Goldfried and Kissel, do not provide useful "tests" of symbol meanings predictions since they fail to differentiate normative from iäiosyncratic aspects of symbol meanings. 
The authors averaged the semantic differential ratings on each scale for each stimulus (symbol) across the Ss population. Using these averages as the "meaning" of the symbol, the authors contrasted the findings with the "meaning predictions" found in theory and clinical literature. These nomothetic meanings provided statistical norms of symbols stimulus qualities, but did not reflect the meaning of the symbol for the individuals in the study. Since it is individuals who use a symbol and since this data summary method did not consider use (meaning) by Ss deviating from the norm, this normative method of determining symbols connotations "does not" provide a "test." of a symbols meaning.

Symbol theory formulations generate hypotheses useful for determining the manner in which an individual uses a symbol and ascribes to the symbol emotional meaning. Universal symbols (sexual shapes predictions by Freud, or archetypes predictions by Jung) have stimulus qualities which allow individuals to attribute meaning. to the universal symbol congruent with their personal meanings associated with the referent which the universal symbolizes. To test the capacity of a universal symbol to represent a certain class of meanings, it is not enough to test the symbol by describing the "stimulus value" of the symbol for the group of people judging the symbol. The stimulus quality of the universal symbol may, in fact, tap the predicted dimension (referent) and allow Ss deviating from the norm to describe their personal meanings for the symbol in terms of their unique history of meanings associated with that referent. For example, if the symbol house is a good symbol for the self-concept, as predicted by Jung (1964), then the connotative qualities used to define the symbol will vary greatly 
from individual to individual. If the relationship between an individual's connotative meanings for house and connotations for self is congruent or closely related, even though quite different from the group norms, the data would support the predicted symbol-referent relationship. When W. G. Klopfer (1954) described a process for determining individual-relevant symbol meanings to Rorschach contents, he contrasted it with "empirical nosological methods useful only for distinguishing between diagnostic groups, but of very little use in the assessment of individual personality characteristic", (Klopfer, 1954, p. 401). In. Pope and Bare's semantic differential investigations of ten popular Rorschach percepts, and four personal concepts, they found that percepts and concepts formed semantically equivalent clusters, that data for the group did not demonstrate semantic overlap (equivalency of percept and concept meanings), but that data for the individuals did demonstrate affective "equivalence categories" and was expressive of personal meanings. Pope and Bare called for use of this procedure as a "method of distinguishing between culturally normative and idiosyncratic aspects of meaning" (Pope and Bare, 1961, p. 392).

The Semantic Differential investigations of sexual noun symbol meanings (Worthy and Craddick, 1969; Archer and Burgess, 1970; Craddick and Worthy, 1970; Althouse, 1970) fail to provide meaningful data for validating Freudian and Jungian theory predictions. The authors have described only normative data, used the least appropriate highly denotative potency scales for determining symbol meanings, and as a "refinement (Archer and Burgess) have used even less appropriate data for making sexual meaning determination using only the masculine-feminine Semantic 
Differential scale. They used data analysis procedures which failed to adequately describe the semantic differential scales ratings. Determinations as to masculinity or femininity of a symbol wëre made by a binary method that often included actual neutral ratings or insignificant deviations from neutrality in making a sexual meaning determination. These authors made a sexual meanings determination based upon the mean rating of all Ss (by sex) for a symbol. If the mean value was 64.00 , a feminine determination was made, if $>4.00$, a masculine one. As Messick (1957) demonstrated, ratings on the Semantic Differential are not integers but intervals with \pm .50 boundaries. When ratings for a population are averaged, neutral means would fall within the range 3.50 to 4.50 and not exactly at 4.00. The authors made 30 in 192 sexual determinations based upon sexual neutral ratings.

These authors have also included non-significant deviations from neutral data when making sexual meanings determination. Based upon normative data reported by Osgood, Suci \& Tannenbaum. (1957), Osgọ, Ware, and Morris (1961) and Triandis and Osgood (1959) mean scale scores must deviate at least one scale score from neutrality (i.e., $<3.00$ or 5.00) before they represent a significant departure from neutrality. In the four studies, the authors used non-significant neutral ratings 94 in 192 times when making masculine or feminine meanings determinations.

The conclusions drawn from these studies are not useful tests of symbol predictions since many of the ratings reported may represent actual neutral ratings or non-significant deviations from neutrality rather than masculine or feminine qualities as their authors imply. 
Osgood and Lauria (1954) and Moss (1970) were able to overcome the nomothetic-idiographic symbol meaning problem by conducting extensive Semantic Differential investigations of specific individuals intra-personal symbol systems. Osgood and Lauria completed a blind analysis of the "Three Faces of Eve" case, in which each of the personalities rated clinically useful concepts (e.g., my mother, my father, love, therapist, etc.) at several times in the course of therapy. A three dimensional model was developed to demonstrate the iterrelationships between the personalities' meanings for the concepts. This model developed from the blind analysis of objective semantic differential meanings material was found to accurately reflect the patients psychological structures and was responsive to personality change which occurred during the course of the therapy as described by the treating therapist.

Moss reported several cases where semantic differential ratings were used to indicate the meaning of significant people in the patient's life as well as dream symbols. Ratings were made while the patient was awake and while the patient was in a hypnotic trance. He found that early in therapy, trance ratings and dream symbol ratings were closer than were waking ratings and aream symbol ratings. As a successful therapy progressed, waking rating, trance ratings, and dream symbol ratings converged. Moss (1961) suggested that congruence of dream symbol ratings and trance ratings demonstrated similarity of symbol usage in unconscious states.

In over 25 years of semantic differential research, only two sources have reported the use of this method to measure individuals 
symbol systems. These studies have described only five individuals symbol structures. Neither investigation reported measuring symbols included in meanings predictions by the personality theorists. The current study was conducted to provide a data base for determining the meaning of some symbols-referents relationships posited by traditional personality theorists. 


\section{CHAPTER III}

RESEARCH DESIGN

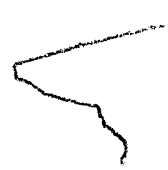

This investigation was conducted to test the validity of some symbol-referent relationsips hypothesized by Freud (1960). Jung (1964), Leuner (1369), Desilile (1965). Fryoughout the precering review of synbol investigations, meihodological linitations and inappropriate proceaures were describea. 'ihe cursent stuäy wias designeá to be methodologically responsive to clinical symbol theory and basic researcin requixements.

bymol theory would require that an investigation of symbol meanings litilize an instrument that taps unconscious levels of mearing. The connotative or affective meanings dimension is the one on which symbols are gererated and the dimension thet maintains the meanings between a symol and its referent or meaning. The semantic aifferential (oggood, 1.962) is the nost opjevive instrument able to tap uncorscious meanings and the best instrument to measure symbols. Use of this instrument dos nut lead to a denotavive-defended response ratirg which mould inhitit syabol meanings determination. Denotative techniques generate data actualiy supporting symol theory but "guanti-

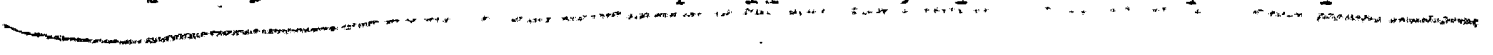
tatively" refuting the symbut mearings prejicted by psychoaralytit ineories.

The Semantic Diffarential technique allows 5 s a sufficient range of meanzings choices are generites data that can be sumarized for all 
Ss. This was not possible in forced choice association methods which limited Ss responses to only a few meanings nor in free association methods which could not summarize and include data for as many as 508 of the Ss giving responses not consistent with the majority of the $\underline{\text { Ss }}$ responses.

This study is unique in that it includes both symbols and hypothesized referents in the concepts to be tested. By generating Semantic Differential meanings for both sets of stimulus concepts, it is possible to directly measure the meanings relationships. In other investigations employing the semantic differential technique to measure symbols, the authors merely derived the average connotations of the symbols and compared these connotative meanings with the meanings described in personality literature. The direct symbolreferent comparisons measured in this investigation strengthen the study and allow more direct conclusions to be drawn about symbol-. referent relationships for the sample of respondents:

In this investigation, there is no confusion between nomothetic and idiographic data summary methods. Nomothetic data, computed by averaging all ratings for the stimulus sets (collapsing ratings across Ss), then using the Ss mean scores as the basis for describing differences between the symbols and referents, is used only as a "popular" or "cultural" level of symbol meanings. No attempt is made to use this data to test symbol-referent relationships predicted from psychoanalytic theories applicable to individual usage.

These popular comparisons are described and used as tests of the symbol theories predictions of culturally stereotyped symbol Lreferent 
relationships.

Data used to test symbol theory predictions about specific symbol-referent relationships is computed for each individual between the stimulus concepts. For every individual the meanings ascribed to each symbol and each referent were quantitatively derived. Then this "relationship" data was summarized with other Ss ratings to determine the average relationship scores between the sets of stimulus concepts for the males and females and the combined groups completing the study.

Through use of these data analysis techniques, the study is methodologically consistent with symbol theory formulations. The data can be differentiated in terms of personal, cultural and universal aspects of meaning as is done in clinical practice.

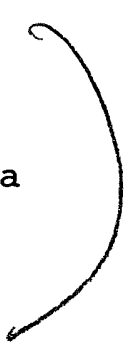

Theoreticaliy, the semantic differential should be the best tool for developing data relevant to the meanings of symbols since this instrument taps data loaded on the connotative or affective meanings dimension. It is, however, possible that this instrument may not adequately tap the layers of personality that determine the unconscious attitudes and symbolic processes of the Ss determining symbol meaning. Also, Semantic differential data may not tap. the dimension the clinician utilized in developing symbol theory formulations and used in clinical practice. Thus, support or refutation of the theoretical symbol-referent relationships may not necessarily constitute a test of validity, but provide indirect quantitative tests of validity. These quantitative indirect tests of validity seem to be theoretically and methodologically responsive to the process the clinician taps in making 
symbol meaning determinations, and seem to describe the process involved in the generation of symbols for the individual.

The specific symbol-referent relationships under investigation include the following:

1) The symbol ASCENT predicted by Jung (1964) and DeSoille (1965) to represent heightened affect, and movement toward conscIous.

2) The symbol COW predicted by Leuner (1969) to represent the meanings associated with MOTHER and the feeling of the relationship with MOTHER(S) in general.

3) The symbol DESCENT hypothesized by DeSoille (1965) and Jung (1964) to represent movement into the UNCONSCIOUS and feelings associate with depression, foreboding and lower affect.

4) The symbol DRAGON predicted by DeSoille to represent the PROHIBITIONS of society and societal constraints. In Freudian terminology to represent the confrontation with the super ego.

5) The symbol ELEPHANT predicted by Leuner (1969) to symbolize the meanings associated with FATHER and represent the feelings of the relationship with FATHER(S) in general or specifically. (In Freudian terminology represents the confrontation with the Father figure or authority figure.)

6) The symbol HOUSE predicted by both Jung (1964) and Leuner (1969) to symbolize the meaning of the self and reflect the self concept or ME ratings.

7) The symbol SWORD hypothesized by DeSoille (1965) and Freud (1952, 1960) to symbolize the self concept for males (ME males) and to represent the feelings toward the masculine aspects of the self and 
masculine aspects in general (FATHER for both females and males.)

8) The symbol VASE hypothesized by Freud (1957, 1960) and DeSoille (1.965) to symbolize the self concept for the female (ME for females) and to represent the feelings toward the feminine aspects of the self and feminine aspects in general (MOTHER for both males and females.)

9) The symbol WITCH predicted by DeSoille (1965) and Jung (1964) to symbolize the relationship with the MOTHER concept in general and aspects of the MOTHER relationship in particular.

10) The symbol WIZARD hypothesized by DeSoille and Jung (1957) to represent the relationship with the FATHER concept in general and the FATHER relationship for the individual in particular.

Data for the symbol-referent relationships will be discussed

for the culturally stereotyped or popular predictions separately from the individually determined or "universal" symbol meaning predictions. . 
CHAPTER IV

RESEARCH METHOD

Stimulus Concepts and Semantic Differential Scales

The stimulus concepts to be rated consisted of 16 nouns. Ten are theoreticaliy symbols which often carry connotative meanings that are not consonant with their denotative definitions. These symbols, as predicted by specific theorists, often have connotative meanings equivalent to the connotative meanings associated with specific referents, but unrecognized to the individual experiencing the symbol. The stimulus concepts hypothesized to be symbols include: ASCENT, COW, DESCENT, DRAGON, ELEPHANT, HOUSE, SWORD, VASE, WITCH and ELEPHANT.

Six of the stimulus concepts are theoretically referents which usually carry denotative and connotative meanings that are consonant. The stimulus concepts that are utilized as referents are: conscIous, FATHER, ME MOTHER, PROHIBITIONS, and UNCONSCIOUS.

Each of the sixteen stimulus concepts was presented at the top of a page followed by sixteen bipolar scales.

The semantic differential scales chosen sampied the three major factors (evaluation, potency, activity) isolated by osgood, Suci and Tannenbaum (1957). Seven scales had high loadings on evaluation: hadgood, awful-nice, ugly-beautiful, unpleasant-pleasant, worthless-valuable, dirty-clean, and healthy-sick. The potency factor was represented by weak-strong, small-large, light-heavy, and deijcate-rugged. Scales with high activity factor loadings were slow-fast, passive-active, 
cold-hot, and dull-sharp. Also included was a scale not factor weighted by Osgood, Suci and Tannenbaum feminine-masculine.

Sets of booklets were constructed in which the stimulus concepts appeared in random order. Sixteen random orders were constructed so that each stimulus concept would appear randomly in any location throughout the booklets. The stimulus concept random presentations would control for any ordering effects involved in the process of working through the booklets reducing the chances of position by concept interactions.

The 7-point scales on each page of the booklet were presented in 16 random orders so that each scale would have an equal likelihood of appearing on any line of the rating page. For each page in the booklets there is a different ordering of the scales. For each stimulus concept the ordering of the scales in each booklet was constant. The random order of scales presented on the pages controls for possible order effects and habituation of response patterns due to scale position on the paiges.

Each presentation of the scales was designed so the scales' endpoints appear in a counterbalancing order of presentation. Each scale endpoint appeared on the left margin an equal number of times throughout the booklet and was equal with the number of times it appeared on the right margin. If good appeared on the left margin in the first presentation, it would equally be found to appear on the right margin throughout the booklet with bad appearing on the left margin. The counterbalancing of endpoints corrects for response tendencies toward ratings highly loaded on either side of the page.

Scales appeared in the following form throughout the booklets: 


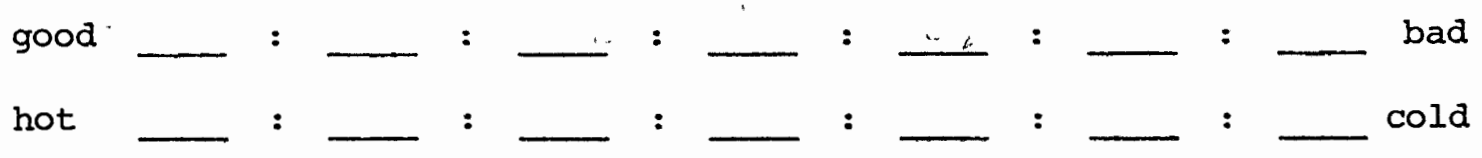

In every case, the stimulus concept appeared centered and at the top of the page. Directions for checking the meaning on the scales were given so that the positions represented a degree of meaning or association with the endpoint of the scale. The quantifiers were very closely associated for the two endpoint positions, quite closely associated for the two positions one in from the endpoint, only slightly related for the two positions on either side of the midpoint and completely irrelevant or equally associated for the middle space on the scale.

Subjects and Adminiştration Procedures

Volunteer Ss from evening psychology classes at Portland state University and Portland Community College participated in the tudy. PSU students were enrolled in a child psychology class which included some graduate students from other than the psychology department. PCC students were enrolled in an introductory psychology class.

Ss's were told they were going to participate in a study of word meanings. Booklets were handed out and oral directions for ratings were given (reading the directions on the cover of the booklet) with the four examples demonstrated on the chalk board. Questions regarding the rating procedure were answered and the Ss were allowed to work on the booklets until completed. Completion time ranged from ten to thirty minutes for the Ss. A total of 65 booklets were collected.

The booklets from the classes were randomized and the first 20 completed booklets for males and 20 completed booklets for females were included in the study. In several cases, booklets could not be used 
due to the Ss failing to make ratings on a page in the booklet. Booklets for other $\underline{S}$ were not included in the study due to the extreme time involved in hand coding the ratings and encoding into computer format.

Femlae $\underline{S}$ ranged in age from 18 to 50 years with a mean age of 27. 25 years. Ten were married, three divorced and seven single. College class status included five freshmen, one sophomore, three juniors, one senior and ten graduate students. Male Ss ranged in age from 17 years to 42 years with a mean of 27.50 years. Thirteen were married, one divorced and six were single. College classes included seven freshmen, three sophomores, three juniors, no seniors and seven graduate students. No attempt was made to draw responses from a homogenous sample. The age range, marital status and college class status variance provided

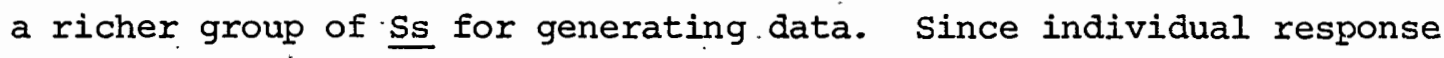
relationships were the main focus of this study, group characteristics are of lesser importance. The diversity of Ss characteristics may more accurately reflect a sample of cultural symbol users than would a sample of "typical college sophomores".

Data Analysis Procedures

Ss's check marks on the scales were converted into numerals ranging from one to seven following the standard semantic differential technique. In all cases, the one (1) value represents the lesser, weaker, or less valued pole. A rating of three would be determined on both of these scales:

good

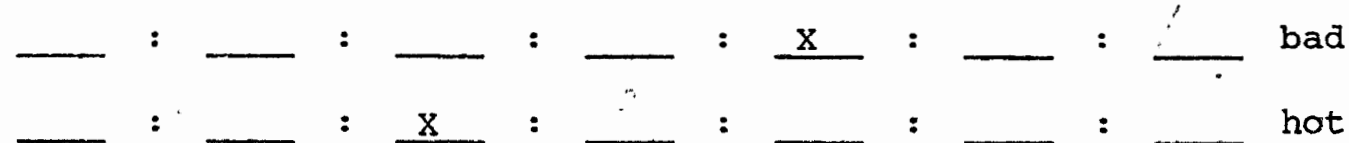

cold

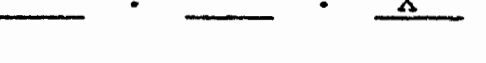


Analysis of the scales was done in terms of the ratings on the original scale. No conversion to factors (evaluation, activity, potency) scores was made. Presley (1969) has shown that until it is demonstrated that the scales have the same high factor loadings for the concepts presented, considerable error is introduced by presenting new concepts and assuming that each bipolar scale will tap the factor as it did for other types of stimulus material. No research has been done to demonstrate that the factors represented by the standard scales (Osgood, 1957) have the same loadings when the stimulus material are noun symbol concepts.

A data summary sheet was constructed for each $\underline{S}$ indicating every rating for every scale for every concept. Each data sheet contained 256 data position entries with each position value ranging from one to seven (16 concepts $\times 16$ scales).

The raw data sheets for each $\underline{S}$ showing each rating were then combined into a single summary sheet for each sex. This was accomplished by averaging each of the 256 data entries for all males and all females. The two summary sheets yielded the mean ratings which indicated direction and degree of meaning. The means were used to determine the significance of the ratings and to generate the normative or "popular" connotations of the symbols.

The second data analysis step invglved using the two sets of mean values derived above as the basis for developing measures of similarity between the stimulus. The normative, "cultural" or "popular" means were compared for each concept with every other concept for each sex separately. The square difference method $\left(D^{2}\right)$ was used as the measure 
of similarity. $\mathrm{D}^{2}$ is obtained by summing the squares of the difference on each scale between the scale positions for the two concepts being compared. For each concept by concept relationships, a single $D^{2}$ was derived. The smaller the $\mathrm{D}^{2}$, the closer the two concepts were rated; the larger the $\mathrm{D}^{2}$, the more dissimilar were the ratings on the concepts. It is possible to describe the normative or cultural relationships between the symbols and referents for the Ss making the ratings through examination of square difference comparisons ranked ordered by the mean values. These relationships descriptions provide quantitative information useful for testing cultural aspects of symbol meaning. The third data analysis procedure used the raw data sheets for each $\underline{S}$ described above. The data was then analyzed in terms of the inter-relationships between the stimulus concepts for each $\underline{\mathbf{S}}$ separately. Thus, the squared differences were computed between the symbols and referents for each $\underline{S}$ in the study. The $D^{2}$ for each concept by concept comparison for each $\underline{S}$ were then used as the basis for deriving a mean summary sheet of $D^{2}$ values for each sex. The mean $D^{2}$ sheets represent the average of the idiosyncratic symbol referent relationships. By not first converting to normative mean values, then computing $\mathrm{D}^{2}$ interrelationships ( as was done in step two above) the data preserves individuals symbol-referent meaning relationships before the data is summarized. Using this individual relevant data which quantifies the symbolreferent relationships it is possible to test symbol theory hypotheses about specific relationships or "universal" meanings. The "universal" meanings would be validated if the hypothesized symbol-referent relation-

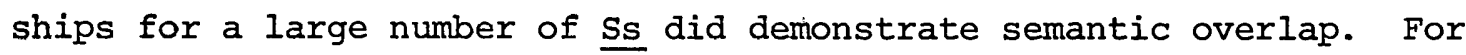


those symbol-referent relationships to be tested, if theory were validated, we could expect a very close ranking between the symbol and its referent. Each symbol was used as the base for rank ordering every other concept. 


\section{CHAPTER V}

\section{RESULTS}

\section{Significance of Ratings and Popular Connotations}

Table I shows the mean scale score ratings for each of the concepts on each of the scales for both males and females. A mean scale score of 3.00 or less and 5.00 or more is a significant deviation from neutrality (Osgood, Suci and Tannenbaum, 1957; Osgood, Ware and Morris, 1961; Triandis and Osgood; 1958) and refers to the polar adjective to the left and the right of the continuum respectively.

Summarizing mean scale scores that deviate from neutrality it is possible to determine if enough scales were significantly used to describe a given concept. Only concepts that were significantly differentiated from one another would be used in making meanings tests. If a concept did not have at least three significant non-neutral responses on the scales, it was not included in the comparisons.

Table II contains a sumary of the significant scales rated on each concept as well as a summary of significant concepts being differentiated on each scale. If a scale did not demonstrate at least three concepts as being significantly different from neutrality responses, the scale was not as useful fox differentiating the concepts.

Scales as used by both sexes significantly differentiated the concepts from one another. Results indicate an average of 8 of 16 significantly non-neutral concepts per scale. One scale, cold-hot for female $\underline{S}$, had sjgnificant ratings on only two concepts. All scales 
Polar Scoreml

\begin{tabular}{|c|c|c|c|c|c|c|c|c|}
\hline & As & ent & $\mathrm{Co}$ & ious & & ow & De & ent \\
\hline & M & $\mathbf{F}$ & M & $\mathrm{F}$ & M & $F$ & M & $\mathrm{F}$ \\
\hline bad & 5.35 & $5.00^{\star}$ & $6.25^{\star}$ & $5.55^{\star}$ & $6.10^{*}$ & $5.65^{\star}$ & 4.60 & 3.80 \\
\hline awful & * & $5.15 *$ & $6.05^{*}$ & $5.25^{*}$ & 4.90 & $5.30 *$ & 4.60 & 3.60 \\
\hline dgly & 15 * & $5.65 *$ & $5.60^{*}$ & $5.25 *$ & 4.55 & 4.55 & 4.15 & 4.15 \\
\hline unpleasant & $5.45 *$ & $5.30 *$ & $6.10^{\star}$ & $5.75^{\star}$ & $5.30 *$ & $5.30 *$ & 4.45 & 3.95 \\
\hline ixty & 4.90 & $5.00 *$ & $5.50^{\star}$ & 4.65 & 4.55 & 4.30 & 4.05 & 4.35 \\
\hline rorthle & $5.70 *$ & $5.35 *$ & $6.10^{*}$ & $6.20 *$ & $6.45^{\star}$ & $6.35^{*}$ & 4.75 & 4.45 \\
\hline $3 i c$ & $5.25^{\star}$ & $5.10 *$ & $6.00 *$ & $6.00 *$ & $5.80 *$ & $5.65^{\star}$ & 4.20 & 3.85 \\
\hline 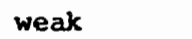 & $5.20 *$ & $5.30^{*}$ & $5.90^{*}$ & 5.50 * & $5.70^{*}$ & $5.40 *$ & 4.15 & 3.95 \\
\hline 1 & $5.00 \star$ & 4.90 & $5.25^{\star}$ & 4.35 & $6.05 *$ & $6.05 *$ & 4.00 & 4.60 \\
\hline & 4.00 & 3.25 & 4.10 & 3.80 & $5.80^{\star}$ & $6.40 *$ & 4.95 & $5.05 *$ \\
\hline & 4. & 4.55 & 3.30 & 3.85 & 4.55 & $5.35 *$ & 4.25 & 4.55 \\
\hline ow & $5.65^{\star}$ & 4.45 & $5.55^{\star}$ & $5.15^{\star}$ & $2.50^{\star}$ & $2.10^{\star}$ & 4.20 & 4.80 \\
\hline ssive & $5.40^{*}$ & $6.00=$ & $6.00^{\star}$ & $5.65^{\star}$ & 3.35 & $3.00 *$ & 4.30 & 4.55 \\
\hline & 4.90 & $5.70^{\star}$ & $5.80^{\star}$ & $5.65^{\star}$ & 3.05 & $2.75^{\star}$ & 3.80 & 3.95 \\
\hline & 4.45 & 3.85 & 4.95 & 4.55 & 4.35 & 4.15 & 3.55 & 3.50 \\
\hline eminine & 4.80 & 4.80 & 4.55 & 3.80 & $2.25^{\star}$ & $2.50 *$ & 4.05 & 3.80 \\
\hline
\end{tabular}

\begin{tabular}{|c|c|c|c|}
\hline \multicolumn{2}{|c|}{ Dragon } & \multicolumn{2}{|c|}{ Elephant } \\
\hline M & F & M & $\mathrm{F}$ \\
\hline $2.95 *$ & 3.65 & $5.30^{\star}$ & $5.35^{*}$ \\
\hline 3.10 & 3.15 & 4.85 & $5.10 *$ \\
\hline $2.15^{\star}$ & 3.15 & 4.25 & 4.45 \\
\hline 2.50 * & $2.95^{\star}$ & 4.80 & $5.30 *$ \\
\hline 3.20 & 3.70 & 3.25 & 3.70 \\
\hline 3.45 & 4.45 & 5.70 * & $5.80 *$ \\
\hline 4.25 & 4.40 & $5.75^{*}$ & $5.80^{\star}$ \\
\hline $6.20^{\star}$ & $6.40^{\star}$ & $6.90 *$ & $6.60^{*}$ \\
\hline $6.25^{\star}$ & $6.60^{\star}$ & $6.90^{\star}$ & $7.00 *$ \\
\hline $6.15^{\star}$ & $5.85^{\star}$ & $6.90 *$ & $6.70 *$ \\
\hline 6.50 * & $6.10^{\star}$ & 6.20 * & 6.35 * \\
\hline 4.50 & 4.95 & $2.50 *$ & 2.30 * \\
\hline $5.30 *$ & $6.40 *$ & 4.70 & 4.00 \\
\hline 4.40 & 4.40 & 3.20 & $2.85^{\star}$ \\
\hline 5.60 * & $5.30^{\star}$ & 4.10 & 3.75 \\
\hline $5.85 *$ & $5.90 *$ & $6.05^{*}$ & 4.70 \\
\hline
\end{tabular}

Father

\begin{tabular}{llll}
$M$ & \multicolumn{1}{c}{$F$} & \multicolumn{1}{c}{$M$} & $F$ \\
$6.25^{\star}$ & $5.65^{\star}$ & $6.30^{\star}$ & $5.70^{\star}$ \\
$6.05^{\star}$ & $5.60^{\star}$ & $6.05^{\star}$ & $5.70^{\star}$ \\
4.90 & $5.10^{\star}$ & $6.15^{\star}$ & $5.40^{\star}$ \\
$5.85^{\star}$ & $5.15^{\star}$ & $6.25^{\star}$ & $5.90^{\star}$ \\
$6.05^{\star}$ & $5.55^{\star}$ & $6.05^{\star}$ & $5.30^{\star}$ \\
$5.55^{\star}$ & $6.15^{\star}$ & $6.50^{\star}$ & $5.90^{\star}$ \\
$5.85^{\star}$ & $5.65^{\star}$ & $5.50^{\star}$ & 4.75 \\
$6.15^{\star}$ & $5.45^{\star}$ & $5.55^{\star}$ & $5.25^{\star}$ \\
$5.75^{\star}$ & 4.90 & $5.80^{\star}$ & $5.15^{\star}$ \\
$5.55^{\star}$ & $5.05^{\star}$ & $5.20^{\star}$ & $5.35^{\star}$ \\
$5.95^{\star}$ & $5.40^{\star}$ & 4.90 & 4.90 \\
$5.80^{\star}$ & 4.70 & 4.10 & 3.70 \\
$5.45^{\star} 5.00^{\star}$ & 4.65 & 3.55 \\
$5.55^{\star}$ & $5.30^{\star}$ & 4.85 & 4.00 \\
4.50 & 4.10 & 4.75 & 4.65 \\
$6.50^{\star}$ & $6.70^{\star}$ & 4.00 & 3.60
\end{tabular}

Polar Score $=7$

good

nice

beautiful

pleasant

clean

valuable

healthy

strong

large

heavy

rugged

fast

active

sharp

hot

masculine

\begin{tabular}{|c|c|c|c|c|c|c|}
\hline & $\mathrm{Va}$ & & Wi & tch & wiz & ard \\
\hline$F$ & $M$ & $F$ & M & $\mathrm{F}$ & $\mathbf{M}$ & F \\
\hline $\begin{array}{l}3.75 \\
3.50\end{array}$ & $\begin{array}{l}5.05^{\star} \\
5.95^{\star}\end{array}$ & $\begin{array}{l}5.45^{\star} \\
5.65^{\star}\end{array}$ & $\begin{array}{l}1.85^{\star} \\
2.25^{\star}\end{array}$ & $\begin{array}{l}3.00 * \\
3.30\end{array}$ & $\begin{array}{l}5.30 \\
4.80\end{array}$ & $\begin{array}{l}4.85 \\
4.85\end{array}$ \\
\hline 4.05 & $5.90^{\star}$ & $5.90^{\star}$ & $1.90^{*}$ & $2.35 *$ & 4.20 & 3.95 \\
\hline 3.60 & $5.60^{\star}$ & $5.85^{\star}$ & $1.95 *$ & $3.00 *$ & 4.95 & 4.65 \\
\hline 4.10 & $5.75^{*}$ & $5.05^{\star}$ & $2.50^{\star}$ & 3.60 & 4.85 & 4.05 \\
\hline 4.05 & $5.65^{\star}$ & $5.45^{\star}$ & $3.00^{*}$ & 4.85 & $5.05^{\star}$ & 4.90 \\
\hline $3.00 *$ & 4.60 & 4.60 & $2.55^{\star}$ & 3.90 & $5.10 *$ & 4.70 \\
\hline 3.35 & 4.00 & 4.85 & $5.10^{\star}$ & $5.00 *$ & $5.60 *$ & $5.25^{\star}$ \\
\hline 4.35 & 3.25 & 4.05 & 3.45 & 4.30 & 4.65 & 4.05 \\
\hline 3.65 & $2.70^{*}$ & 3.30 & 3.55 & 3.85 & 4.55 & 3.60 \\
\hline 3.70 & $1.90^{\star}$ & $2.10^{\star}$ & 4.85 & 4.85 & 4.75 & 4.40 \\
\hline 3.10 & 3.85 & 3.85 & 4.90 & $5.05^{*}$ & $5.40^{\star}$ & $5.30 *$ \\
\hline $2.25 *$ & 3.50 & 3.15 & $5.50 *$ & $5.85^{*}$ & $6.00 *$ & $5.90 *$ \\
\hline 3.10 & 4.25 & 4.30 & 4.85 & $5.30 *$ & $5.90 *$ & $5.70 *$ \\
\hline 3.35 & 3.40 & 3.45 & $2.45^{\star}$ & 3.85 & 4.60 & 4.20 \\
\hline
\end{tabular}

good

nice

beautiful

pleasant

clean

valuable

healthy

strong

large

heavy

rugged

fast

active

sharp

hot

masculine

*indicates a deviation from neutrality (ie 4.00) which is significant at the .05 level. Values less than 4.00 refer to the adjective to the left of the continuum, and values greater than 4.00 refer to adjectives to the right. 
TABLE II

SUMMARY OF SIGNIFICANT SCALES AND CONCEPTS BY SEXES

$\quad$ sCALES
bad-good
awful-nice
ugly-beautiful
unpleasant-pleasant
dirty-clean
worthless-valuable
sick-healthy
weak-strong
small-large
light-heavy
delicate-rugged
slow-fast
passive-active
dull-sharp
cold-hot
feminine-masculine

\begin{tabular}{c} 
MALE SS \\
\hline $12 *$ \\
8 \\
8 \\
11 \\
7 \\
12 \\
10 \\
11 \\
9 \\
6 \\
6 \\
9 \\
9 \\
6 \\
4 \\
10
\end{tabular}

\begin{tabular}{r} 
FEMALE \\
\hline 10 \\
9 \\
8 \\
12 \\
6 \\
10 \\
8 \\
12 \\
5 \\
6 \\
5 \\
7 \\
11 \\
10 \\
2 \\
9
\end{tabular}

\section{CONCEPTS}

ASCENT

CONSCIOUS

COW

DESCENT

DRAGON

ELEPHANT

FATHER

HOUSE

ME

MOTHER

PROHIBITIONS

SWORD

UNCONSCIOUS

VASE

WITCH

WIZARD

\section{MALE SS}

FEMALE SS

10
10
13
1
8
11
13
9
11
12
1
8
2
8
8
5

${ }^{*}$ The entry in the table is the total of significant scales or concepts out of the 16 possible scores. 
for male Ss had significant rating on at least four or more concepts. Concepts were significantly differentiated from each other by the number of scales having non-neutral ratings for each concept. Results indicate an average of 8 of 16 significantly non-neutral scales per concept. Several concepts did not meet the criterion of at least three significant scales for each sex and were not included in the meanings comparisons. DESCENT had no significant scale ratings by male Ss and only one by female Ss. PROHIBITIONS had only one scale significantly deviating from neutrality for each sex. UNCONSCIous had no scales with significant ratings by males and only two scales with non-neutral ratings by females. These three concepts were determined not to have significant non-neutral meanings and were not included in the symbol-referent comparisons for either sex.

For each of the significant ratings, the intensity of the rating may be described by means of the quantifiers "very", "quite", and "slightly", which were used to represent the scale positions in the instructions to the $\underline{S s}$. These connotations of the stimulus represent the "popular" or average connotations for the Ss by sex.

Table III presents these quantifiers as they apply to the scale units. Each of the scale units does not represent an absolute value, although it is assigned an integer. It actually represents an integer with boundaries \pm .5 (Messick, 1957). Therefore, it is possible to determine the intensity of mean ratings by placing them on the scale with intervals given to represent the limits of the scale position. Table I indicates that the mean ratings for ASCENT on the goodbad scale was 5.35 for males and 5.00 for females. These means are 
TABLE III

QUANTIFIERS CORRESPONDING TO EACH SCALE UNIT

\begin{tabular}{|c|c|c|c|c|c|c|}
\hline .5 & & 2.5 & & 4.5 & & 6.5 \\
\hline 1 & 2 & 3 & 4 & 5 & 6 & 7 \\
\hline$v$ & quite & slightly & - & slightly & quite & rery \\
\hline
\end{tabular}

statistically significant (i.e., >5.00) and since they both fall within the limits of 4.5 to 5.5 , it indicates that both male and female $\underline{\mathrm{Ss}}$ categorized ASCENT as being "slightly good". Appendix Table VII contains a summary of the popular significant connotations for the combined sample and for each sex separately.

Comparison of the significant ratings of male and female $\underline{\text { s }}$ reveals reversals in direction for only one concept. For ME females rated the concept as feminine while males rated it as masculine. In all other cases, if the stimulus was rated by one sex in a polar direction, the other sex also rated it in that direction or showed no significant rating at all.

The only symbol included in this study and included in previous semantic differential studies was cow. It was found in Goldfried and Kissel's (1963) study to be viewed by males as quite good; slightly strong, feminine and slow. Female ss rated cow as very good; quite feminine and slow. Male and Female ratings combined described it as quite large and slightly passive. Cow in Goldfried's (1963) study was found by males and females to be rated quite good, large, feminine and slow. In the present study for the same scales, cow was found to be quite good, large, feminine, strong and slightly slow by male Ss. Female Ss rated it as quite good, large, slow; slightly 
strong, feminine and passive. Male and Female ratings combined were quite good, strong, large, slow and feminine. For the symbol cow, the three populations showed considerable agreement in connotative meanings ratings.

In the traditional method of semantic differential studies, the connotations described in Appendix Table VII would be contrasted with qualities of symbols developed in clinical theoretical literature. The authors would draw comparisons between the symbols and the meanings as "validated" in their study by contrasting the connotations with obvious qualities predicted by symbol theories. For instance, to test the validity of the use of the symbol SWORD as a masculine symbol, the connotations would be described. In Appendix Table VII the connotations of Male Ss for SWORD were very sharp; quite strong, rugged, fast and masculine; slightly valuable, active, large and cold. Female Ss connotations were very sharp; quite strong, fast and cold; slightly valuable, large and masculine. Both Male and Female Ss describe SwORD as masculine with males describing it as more masculine than females (i.e., quite masculine by Male Ss and slightly masculine by female Ss.) The other qualities attributed to the symbol are generally connotations attributed to masculinity more often than femininity (i.e., sharp, strong, rugged, fast, active and large) and support the symbol as masculine and support psychoanalytic theory.

Through the inclusion of both symbols and referents in the present study it is possible to go beyond a comparison of connotations with qualities ascribed in literature to actual comparisons of the symbols closeness of fit with the referents predicted in the literature. In 
Results, Normative or Popular symbol-referent relationships, the quantitative difference between the mean ratings of the ss for symbols and for referents is compared directly.

Normative or Popular Symbol-Referent Relationships

Appendix Table VIII shows the squared difference scores $\left(D^{2}\right)$ between the symbols and referents for Male Ss. $D^{2}$. were computed between the stimulus concepts using the mean values described for Male $\underline{\text { Ss }}$ in Table $I$. The $D^{2}$ of 6.56 between ASCENT and CONSCIOUS in Appendix Table VIII is the sum of all squared difference comparisons for all sixteen scales. On the bad-good scale, Male $\underline{\text { Ss }}$ average rating for ASCENT was 5.35 and CONSCIOUS was 6.25. The difference between the mean ratings is .90 and the $d^{2}$ is .81 . This $d^{2}$ is summed with the $.42 \mathrm{~d}^{2}$ between ASCENT and CONSCIOUS for the awful-nice scale (ASCENT mean 5.40; conscious mean 6.05; difference $.65 ; \mathrm{d}^{2}$ equals .42 on the awful-nice scale).

Continuing this procedure through all sixteen rating scales, the summary $D^{2}$ between ASCENT and CONSCIOUS is 6.56 . This $D^{2}$ is the second smallest for all stimulus distance comparisons with ASCENT (the smallest is. between ASCENT and WIZARD at 5.72 ) when reading down the first Column on Appendix Table VII.

All possible combinations of distance measures between the sixteen concepts (symbols and referents, symbols and symbols, referents and

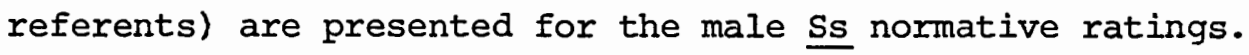

Symbols, which should have the same meaning as their hypothesized referents, should have small squared difference scores compared with the theoretical referent. 
Appendix Table IX contains a summary of Popular or Normative squared difference distances between symbols and referents for Male Ss. In this Table, the ten hypothesized symbols are presented along the left margin with the closest fitting symbols or referents ordered from the symbols. In the first row, the symbol ASCENT has the smallest possible $D^{2}$ when compared with WIZARD (5.72) also a symbol. The second closest concept is conscious $(6.56)$ which is underlined because it is theoretically the referent for the symbol ASCENT. The third closest fitting concept is $\mathrm{ME}(10.78)$ and so on up to the seventh most similar meaning concept SWORD (15.59). Since this investigation is interested in assessing the closeness of meaning between symbols and their referents, ordinal positions beyond the seventh were not considered useful. These positions can be derived from ordering the $\mathrm{D}^{2}$ for the symbol in Appendix Table VIII for Male Ss. The $D^{2}$ 's range over a 79.49 value scale of similarity on the ASCENT comparisons for Male $\underline{S s}$. The hypothesized referent for the symbol ASCENT appears second closest to the symbol and is $6.56 \mathrm{D}^{2}$ units from the symbol. While the referent proves not to be the closest concept to the symbol, it is the closest referent to the symbol. The closest concept to the symbol is another hypothesized symbol WIZARD (5.72). This data comparison procedure was used in making all other symbol referents comparisons.

Appendix Table $\mathrm{x}$ contains the squared difference values between the symbols and referents for Female Ss normative or popular ratings. Appendix Table XI presents the summary of distances from the symbols for the popular ratings of the Female $\underline{\text { Ss. }}$

Appendix Table XII contains the Popular or Normative $D^{2}$ between 
symbols and referents for the combined sample of male and female Ss. Appendix Table XIII presents the summary of distances from the symbols for the popular ratings of the sample. TABLE IV contains a summary of the ranks for the hypothesized symbol-referent relationships predicted by symbol theories to be equivalent in meanings. This table indicates the degree to which the symbol and referent were ordered in closeness for the male, female and combined normative or popular ratings presented in Appendix Tables VII through XIII.

TABLE IV

NORMATIVE OR POPULAR RANKINGS FOR HYPOTHESIZED SYMBOL-REFERENT COMPARISONS

\begin{tabular}{|c|c|c|c|}
\hline & MALE RANKS & FEMALE RANKS & COMBINED \\
\hline ASCENT $\mathrm{X}$ CONSCIOUS & 2nd & lst & lst \\
\hline COW X MOTHER & 8 th & 11th & 10th \\
\hline DESCENT $\mathrm{X}$ UNCONSCIOUS & n.s. & n.s. & n.s. \\
\hline DRAGON X PROHIBITIONS & n.s. & n.s. & n.s. \\
\hline ELEPHANT $X$ FATHER & 2nd & $3 r d$ & $3 r d$ \\
\hline HOUSE $\times \mathrm{ME}$ & 4 th & 6 th & lst \\
\hline SWORD X ME & 4 th & & \\
\hline SWORD X FATHER & $3 r d$ & 5 th & 3 rd \\
\hline VASE X ME & & 2nd & \\
\hline VASE X MOTHER & lst & $3 r d$ & 1st \\
\hline WITCH X MOTHER & 10th & 10th & 8th \\
\hline WIZARD X FATHER & $3 r d$ & 3 rd & 2nd \\
\hline
\end{tabular}

TABLE IV does not contain rankings for concepts found not to differ significantly from neutrality. In summarizing the rank orders of closeness of symbol with hypothesized referent there is a trend for hypothesized relationships being found in the first several ranks. For the combined male and female Ss normative ratings the symbol ASCENT was found to be closest to its referent CONSCIOUS. COW did not 
represent MOTHER. DESCENT for UNCONSCIOUS and DRAGON for PROHIBITIONS could not be compared due to lack of significance of ratings on original scales. ELEPHANT as a symbol for FATHER was third closest, while WIZARD as a symbol for FATHER was second closest. SWORD as a symbol for FATHER was also third closest. HOUSE as a symbol for ME proved to be the closest fitting relationship for the combined male and femaie ratings. VASE proved to be the best symbol for MOTHER and WITCH failed as a symbol at eighth place. SWORD was a good ME symbol for male Ss as was VASE for female Ss.

Insofar as the subjects in the sample may represent the symbol using culture, the normative or popular meanings relationships should reflect the cultural meanings attributed to the symbols. These popular meanings of the symbols could be utilized by many people in the culture to symbolize their unique personal meanings associated with the specific referent. FATHER meanings could be symbolized by WIZARD, SWORD, or ELEPHANT. MOTHER meanings by VASE. CONSCIOUS bY ASCENT. ME or selfconcept could be symbolized by HOUSE for both sexes, by SWORD for male Ss and VASE for female Ss.

Meanings attributes ascribed to these symbols in dreams and fantasy would easily parallel the personal meanings associated with the theoretical referent for many individuals in the culture.

\section{Idiosyncratic Symbol-Referent Relationships}

Appendix Table XIV contains the average of individual squared difference values for the Male Ss. $D^{2}$ were derived from the average of the individual $\mathrm{D}^{2}$ between each concept for each male subject. The $\mathrm{D}^{2}$ of 50.35 between ASCENT and CONSCIOUS is the average of all individual. 
$D^{2}$ for the two concepts. The $D^{2}$ is computed based upon the actual individuals symbol-referent distance rather than the average rating for each symbol and referent.' In this way, the information about individual's symbol-referent relationships is maintained and the descriptive $D^{2}$ represents an average of the relationships. Idiosyncratic information is preserved in the array of $D^{2}$ of which the Appendix Table XIV entry represents the mean.

Reading down the first column of Appendix Table XIV, the smallest $\mathrm{D}^{2}$ is between ASCENT and CONSCIOUS and the largest is between ASCENT and WITCH (50.35 and 133.65 respectively) all other comparisons with ASCENT are presented. Since symbols are referents should have the same connotative meanings, hypothesized symbol-referent relationships squared differences should be small.

Appendix Table XV contains a summary of Individuals $D^{2}$ 's between symbols and referents for Male Ss. In this table, the ten hypothesized symbols are along the left margin with the closest fitting symbols or referents ordered from the symbols. In the first row, the symbol ASCENT is closest to the referent ConscIous (50.35) which is underlined because it is theoretically the referent for the symbol.

Thus, for the Male Ss, the average of the symbol-referent relationships between ASCENT and CONSCIOUS is smaller than the average of any other symbol-symbol or symbol-referent relationships compared to ASCENT. The next concept having closest similarity to ASCENT is HOUSE, a referent with an average $D^{2}$ of 58.75 . The range of $D^{2}$ is 83.30 for all comparisons with ASCENT. The other symbol-referent comparisons are also presented. 
Appendix Table XVI contains the averages of individual $D^{2}$ values for Female Ss. Appendix Table XVII presents the summary of distances from the symbols for the female ss idiosyncratic $\mathrm{D}^{2}$ relationships averages.

Appendix Table XVIII contains the averages of the individuals $D^{2}$ between symbols and referents for the combined male and female Ss. Appendix Table XIX presents the summary of distances from the symbols for these average individual relationships.

Table $V$ contains a summary of the ranks for the symbol-referent relationships predicted by theory to be equivalent in meanings. This table indicates the degree to which the symbol and referent were ordered in closeness for male, female and the combined sample on the Average of individuals relationships presented in Appendix Tables XIV through XIX.

TABLE V

AVERAGE OF INDIVIDUALS' SYMBOL-REFERENT RELATIONSHIPS FOR HYPOTHESIZED COMPARISONS

MALE RANKS FEMALE RANKS COMBINED

\begin{tabular}{|c|c|c|c|}
\hline ASCENT $X$ CONSCIOUS & lst & lst & lst \\
\hline COW X MOTHER & 9 th & 7 th & 8 th \\
\hline DESCENT X UNCONSCIOUS & n.s. & n.s. & n.s. \\
\hline DRAGON X PROHIBITIONS & n.s. & n.s. & n.s. \\
\hline EIEPHANT X FATHER & 2nd & 6 th & $3 r d$ \\
\hline HOUSE X ME & 2nd & $2 n d$ & 2nd \\
\hline SWORD X ME & $3 r d$ & & \\
\hline SWORD X FATHER & 2nd & 8 th & 4 th \\
\hline VASE X ME & & lst & \\
\hline VASE X MOTHER & lst & 5 th & $2 n d$ \\
\hline WITCH X MOTHER & 9th & 10th & 10th \\
\hline WIZARD X FATHER & 4 th & 5 th & 5 th \\
\hline
\end{tabular}

In the summary of individuals symbol-referent relationships, 
Table $\mathrm{V}$ shows a trend in hypothesized relationships being found in the first several ranks closest in meaning between symbol and referent. Insofar as the subjects in the study are actually symbol users, the summary of their individually described symbol-referent relationships should provide a basis for determining if the theoretically universal symbols are, in fact, used as symbols for hypothesized referents. The following symbols were found to be equivalent in meaning to their theoretical referent and are likely to be universal symbols for the referent. CONSCIOUS and the meanings associated with it could be symbolized by ASCENT. MOTHER could be symbolized by VASE but not WITCH or COW. FATHER could be symbolized by ELEPHANT, SWORD or WIZARD. This relation-

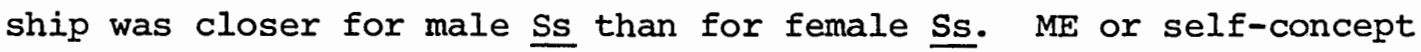

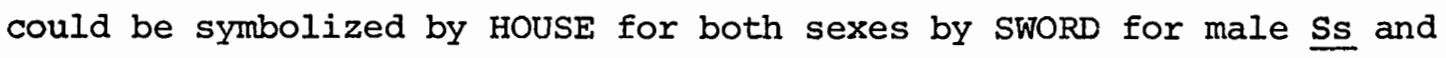
VASE for female Ss.

Some of the symbols have natural opposites in meaning, which when set out in select comparisons more fully demonstrate the closeness of association and equivalency of meaning for the symbol-referent relationships hypothesized. The average ranks of individuals symbol-referent relationships were used in Table VI to demonstrate the symbol-referent relationships validity when presented in contrasted comparisons.

When examining the contrasted comparisons in Table VI, the theoretical formulations having greatest validity tend to have small rankings for the theory correct contrast and large rankings for the theory opposite comparison. When the theory is only partially supported and the symbol and referent are not highly equivalent in meaning, the theory correct and theory opposite rankings are closer together and closer to a random average ranking of 7.5 th. 
TABLE VI

CONTRASTED COMPARISONS USING INDIVIDUALS' SYMBOL-REFERENT RELATIONSHIPS AVERAGE RANKINGS

THEORY CORRECT COMparison VS. THEORY OPPOSITE

ASCENT $X$ CONSCIOUS

vS. ASCENT $\mathrm{X}$ UNCONSCIOUS

COW X MOTHER

vS. COW X FATHER

DESCENT $X$ UNCONSCIOUS

vS. DESCENT $X$ CONSCIOUS

ELEPHANT $X$ FATHER

vS. ELEPHANT $X$ MOTHER

SWORD X ME

vS. VASE X ME

SWORD X FATHER

vS. SWORD X MOTHER

VASE X MOTHER

VS VASE X FATHER

WITCH X MOTHER

vs. WITCH X FATHER

WIZARD $X$ FATHER

vS WIZARD $X$ MOTHER

ELEPHANT X ME

vs. $\mathrm{COW} X \mathrm{ME}$

WIZARD X ME

vs. WITCH X ME

*reversed for female Ss.

MALE

Ist

ns.

9 th

ns.

2nd

1st

$9 t h$

7 th

6 th

ns.

14th

9 th

11th

10 th

15th
FEMALE

CORRECT OPPOSITE

Ist

ns.

7 th

ns.

th

8 th

5 th

5 th

10 th*

loth

11 th*

ns.

15 th

10 th

15 th loth

COMBINED

CORRECT

OPPOSITE

Ist

ns.

8th

12 th

ns.

ns.

$3 r d$

14 th

5 th

5 th

4 th

$14 \mathrm{th}$

2nd

11th

9 th

15th

5 th

13 th

9 th

7 th

4 th

14 th

$9 t h *$ 
CHAPTER VI

DISCUSSION

The results of this study suggest that for this sample the Freudian universal sexual noun symbols tended to be validated. SWORD proved to be a good FATHER symbol and self-concept ME symbol for male Ss. VASE was validated as a ME symbol, but not a MOTHER symbol for female Ss. Male Ss, however, validated VASE as a MOTHER symbol. The Freudian symbols were validated more by male Ss than by female $\underline{\text { Ss. }}$

Throughout this study, male $\underline{\text { Ss }}$ consistently made slightiy more significant ratings than the female Ss (138 significant ratings vs.

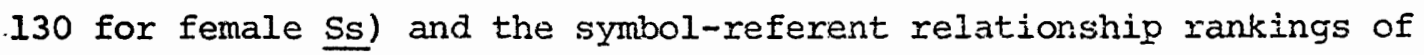
male Ss was closer than for female Si.

The closeness of the male Ss symbol-referent relationships may be due to a trend of the males to make more stereotyped responses to sexual symbolism than the female Ss. The consistent tendency of male Ss to validate both male symbols and female symbols postulated by Freud, also a male, may validate a masculine.symbolism theory perspective.

The fact that female $\underline{S}$ sesults tended not to validate the Freudian symbolism for either masculine or feminine symbols may be because female Ss have less stereotyped symbol expression or do not use symbols for sexual meaning that are generated by the physiognomic resemblances postulated by Freud.

The study results provide support for one of Leurner's (1969) 


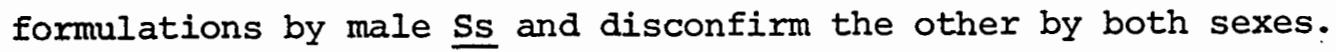
ELEPHANT proves to be a strong FATHER symbol for Male $\underline{\text { Ss but not }}$ masculine self-concept ME males. Female Ss do not support ELEPHANT symbolism. COW is not a good MOTHER symbol for either sex nor a selfconcept ME symbol for female Ss. Results disconfirm the hypothesized symbolization and suggest caution in accepting Leurner's (1969) infantile regression's hypothesis as a basis for symbol determination. The support of the ELEPHANT-FATHER symbolism by male Ss may be another confirmation of a Freudian sexual stereotyped response by male $\underline{\text { S }}$ and provide validity for a masculine generated sexual symbol perspective. The results of this study suggest validation for some of the symbol predictions of Jung. (1968) and DeSoille (1965), while others are disconfirmed or not validated by virtue of non-significance of meanings. ASCENT is a good symbol for CONSCIOUS for each sex. DESCENT had non-significant meaning as did unConscIous. Results for these concepts were not valid tests of the hypothesized relationships.

In this culture, unCONSCIOUS has no generally understood connotations that evoke a stereotyped response. Individuals in the study rated the concept with much variability although the normative data reduced to neutrality of meaning. A frequency response of all 40 Ss in the sample was made of the ratings to unConscIous. The responses were distributed over the seven point scales as follows: 631 's; 90 2's; 105 3's; 2214 's; 62 5's; 65 6's; and 34 7's. This data range reflects many significant ratings. When the individuals profiles were examined, $25 \mathrm{Ss}$ were found to rate the concept mainly on 4 or lower; 6 SS to rate the concept clustered evenly around 4 and 9 Ss to rate 
the concept on 4 or higher. Yet, when the data was reduced to a summary statistic, the average rating of all scales on UNCONSCIOUS was 3.71 or neutrality.

The data as presented in the individual's relationships section, may actually support DESCENT-UNCONSCIOUS symbolism, but may not be determined within the methods of this investigation.

The Jungian archetypal symbol WIZARD proved to be a validated FATHER symbol for both male and female $\underline{\text { Ss }}$ and a self-concept symbol for males. WITCH was not a MOTHER symbol for either sex nor was it a self-concept symbol for females. While the results suggest support for one archetype and non-support for the other, they may have been skewed by culturally stereotyped responses. Ss may have made predominantly positive connotation responses to FATHER, WIZARD and MOTHER and very negative responses to WITCH. The overwhelming negative connotations associated with WITCH, in this culture, may have generated so much negative stereotyped meaning that personal meanings ratings were not reflected. As Jung and DeSoille use the symbol the old magic woman or SORCERESS or WITCH will carry the Ss' meanings associated with the MOTHER. If NEGATIVE MOTHER had been the referent, the Ss may have generated connotations more in keeping with WITCH symbolism. The choice of SORCERESS as the symbol may have evoked ratings more open to personal meanings and provided a better test of the symbol-referent relationship.

Jung, Leurner and DeSoille all use the symbol HOUSE as a ME self-concept symbol. This symbol was consistently validated by both males and females. As was the case for other of the symbol-referent 
relationships the degree of relatedness between the symbol (HOUSE) and hypothesized referent (ME) was closer for the individuals relationships data (both 2nd) than for the cultural meanings (4th males and 6 th females). This finding supports the methods of data comparison employed to validate symbol-referent relationships separate from the cultural meanings relationships.

As the data level used to compare the symbols and referent was closer to expressing individual's symbol-referent relationship there was a tendency for the data to validate more the theoretical predictions for the male $\underline{\mathrm{Ss}}$ data. The female $\underline{\mathrm{Ss}}$ data tended to be a better predictor at the cultural level.

When examining those symbol-referent relationships that were validated more at the individual's data level for each sex, a trend emerged. For male Ss, relationships supporting symbolism for $M E$, FATHER and CONSCIOUS were usually closer. For female Ss, relationships supporting symbolism for $\mathrm{ME}$ and MOTHER were closer at the individual's level and symbolism for FATHER less close. With the exceptions of HOUSE and VASE as ME symbols for females, the hypothesized symbolreferent predictions for females tended not to be confirmed at the individual's relationships data level. This suggests that theory predictions of masculine symbols and of feminine symbols for males may be more indicative of male orientation than of universal symbolism. The fact that masculine symbols are less confirmed for female Ss at the individual relationship data suggest that females do not use "masculine symbols" as much as theories would predict. Female Ss data may reflect masculine symbolism at a "cultural level" because 
females understand but do not use stereotyped masculine symbolization or because at a cultural level there is a masculine symbolism overlay. The current study was based upon the assumption that.symbolism as a process does occur and that some concepts are symbols and some referents. When examining the finding describing the extent of the closeness between a symbol and any other concept for individuals relationships data (Appendix Tables XVI, XVII, and XIX)a. general association paradigm might also explain some of the relationships. If we were to predict that the concepts would be related by animals to animals, people to people and objects with objects; we find that cow and ELEPHANT are closer relationships than either as a symbol for human referents. DRAGON is closely associated to ELEPHANT for male Ss and to SWORD for female Ss.

WITCH is closest to DRAGON for female $\underline{\mathrm{Ss}}$ and to WIZARD for male Ss. These might be explained as being common folk and children's stories associations. WIZARD is closest to ME males and ASCENT females one example of the people-people association.

The prediction of objects associated with objects is not supported.

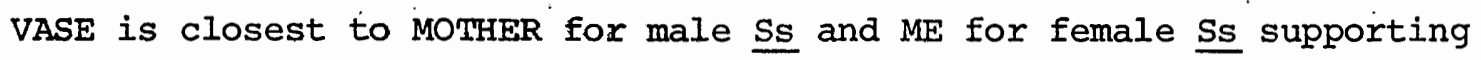
Pyschoanalytic theory predictions. SWORD is closest to WIZARD for male Ss and ASCENT females. The SWORD-WIZARD relationship might be a validation of Psychoanalytic predictions and common children's story relatedness. HOUSE is closely related to conscrous for males and Cow for females not supporting a general associations hypotheses. Although other explanations of concept-concept relatedness may be generated that describe some of the findings the paradigm of symbolism 
and symbol-referent relationships used in personality work was presented and tested by this study.

The present investigation represents a significant development in the symbol validation research in that it presented both symbols and referents to subjects for meanings ratings. The use of semantic differential ratings and scale by scale comparisons allowed for ample individual responses in as differentiated comparisons as possible. By not collapsing the scales data to two or three factors, comparisons were more representative of individuals meanings. The inclusion of a diverse sample of respondents in the study increased the likelihood of symbol users and of many symbol experiences. The use of data analysis. methods including both normative and individual relationships averages allowed, for the first time, an exploration of the question of the differentiation of cultural symbols from individual or theoretically universal symbols.

The study is limited in several respects. There was no differentiation made between symbol users from non-symbol users for the . symbols investigated. The mixing of both symbol users and not users may have canceled significant trends in data. This investigation, like all studies using several subjects, must at some time average across the Ss. Relationships between symbols and referents were preserved as far as possible within the data collection and analysis steps. The "Individual's relationships findings" was based upon the average of the relationships. Thus, the "Individual's relationship findings" and the "Normative findings" differ by one level of summation and may not reflect the difference between individuals who ascribe certain meanings 
to. symbols compared with culturally shared symbols having shared meanings for many individuals.

A problem that plagued the results of this investigation was that of significance of ratings for the averages. In several cases, symbols and referents could not be compared because the average of the ratings on the scales were not \pm 1 from neutrality. For the Normative findings, no statement about meanings could be made. In examining individual data summary sheets it was found that for some subjects, significant relationships did exist between the symbols and referent. Thus, for some individuals, symbol-referent meaning relationships did exist that were not reflected in the normative summary of the data or in the "Individual's Relationships average" data. These individual relationships may have been few in number, may have had polar values and thus canceled each other out, or may have been negated by many individuals who were non-symbol users who did not rate the specific symbol and referent as having meanings.

A possible limiting assumption included in this and other paper and pencil investigations of symbolism, was that the stimulus concepts, e.g., words on a page, would evoke the imagery and emotional meaning involvernent as is found in personal symbol experiences. The very nature of the meanings of symbols may be as much a function of the process of their realization in dreams, daydreams or altered states of awareness as it is their content representation. Thus, a booklet with words at the top of each page may not evoke the meanings sufficient for relationships to be fully scaled.

The objective, quantifiable methods developed in this research 
for measuring symbol-referent meanings are built upon and refined from previous objective investigations of symbol meanings. Use of these methods suggest an area of research capable of yielding objective verification of symbol theory formulations and meanings interpretations developed in clinical practice and literature.

The symbol meanings validated in this study might be used as general meanings hypotheses useful in helping a client determine personal symbol meanings. The clinician must not assume the client is ascribing the universal meaning to the symbol and must further test the clients personal meanings associations to the symbol. The use of the validated symbols in guided fantasy techniques may well evoke responses representative of clients meanings for the referents. This method of symbol-referent comparisons employed in this study could be used to help individual clients map the unconscious relationships between dream symbols, projective techniques symbol responses, guided fantasy symbols, and meaningful personal referents. Clinicians could employ this method to help patients determine personal meanings of symbols and to differentiate personal from cultural and universal components of symbolism. 


\section{BIBLIOGRAPHY}

Adler, G. 1948. Studies in Analytical Psychology, London: Routledge and Kegan Paul.

Archer, G. S., \& Burgess, 1970. I.S.A. Further Investigation of Sexually Symbolic Concepts Using the Semantic Differential Technique, Journal of Projective Techniques \& Personality Assessment, 34, 369-372.

Acord, D. 1962. Sexual Symbolism as a Correlate of Age. Journal of Consulting Psychology, 26, 279-281.

Althouse, R. N. 1970. A Semantic Differential Investigation of Sexually Symbolic Concepts: Freud and Jung. Journal of Projective Techniques and Personality Assessment, 34, 507-512.

Barker, E. D. 1957. The Perception of Sexual Symbolism, Unpublished doctoral dissertation, Columbia university.

Bartlett, F. C. 1932. Remembering, London: Cambridge UniversityPress.

Buss, A. N., \& Durkee, A. 1957. The Association of Animals with Familial Figures, Journal of Projective Techniques \& Personality Assessment, 21, 366-371.

Craddick, R. A., \& Worthy, M. 1970. Reply to Archer and Burgess on Their Investigation of Symbolic Concepts Using the Semantic Differential Technique. Journal of Projective Techniques and Personality Assessment, 34, 373-374.

DeSoille, R. 1965. The Directed Daydream, (Translated by Frank Haronian), New York: Psychosynthesis Research Foundation, Issue No. 18.

Earl, C. J. C. 1941. A Note on Validity of Certain Rorschach Symbols, Rorschach Research Exchange, 5, 51-61.

Freud, Sigmund 1952. (Translated by James Stachey) On Dreams, New York: W. W. Norton.

Freud, Sigmund 1953. Fragment of an Analysis of a Case of Hysteria (1905). In J. Stachey (Ed.), The Standard Edition of the Complete Psychological Works of Sigmund Freud, Vol. 7, London: Hogarth. 
Freud, Sigmund 1960. The Interpretation of Dreams, (Translated by J. Stachey), New York: Basic Books.

Fromm, Erich 1951. The Forgotten Language, New York: Holt, Rinehart $\&$ Winston.

Gill, w. S. 1967. Animal Content in the Rorschach, Journal of Projective Techniques and Personality Assessment, 31, 49-56.

Goldfarb, W. 1945. The Animal Symbol in the Rorschach Test and an Animal Association Test, Rorschach Research Exchange, 9, 8-22.

Goldfried, M.R. 1963. The Connotative Meaning of Some Animal Symbols for College Students, Journal of Projective Techniques and Personality Assessment, 27, 60-67.

Goldfried, M. R., \& Kissel, S. 1963. Age as a Variable in the Connotative Perceptions of Some Animal Symbols, Journal of Projective Techniques \& Personality Assessment, 27, 171-179.

Jones, A. 1956. Sexual Symbolism and the Variables of Sex and Personality Integration, Journal of Abnormal and Social Psychology, 53, 187-190.

Jones, A. 1961. Sexual Symbolic Responses in Prepubescent and Pubescent Children, Journal of Consulting Psychology, 25, 383-387.

Jones, E. 1948. Papers on Psychoanalysis, London: Bailliere, Tindall Cox.

Jung, C. G. 1957. The Collected Works of C. G. Jung, Princeton: Princeton University Press.

Jung, C. G. , Henderson, J. L., von Franz, M. S., Jaffe, A., \& Jacobi, J. 1964. Man and His Symbols, Garden City: Doubleday.

Klopfer, W. G. 1954. Interpretative Hypotheses Derived from the Analysis of Content. In Klopfer, B.; Ainsworth, M. , Klopfer, W. G. , \& Holt, R., Developments in the Rorschach Technique, Volume I, New York: World Book Company.

Leuner, Hanscarl 1969. Guided Affective Imagery (GAI), American Journal of Psychotherapy, 23, 4-22.

Lessler, K. 1962. Sexual Symbols; Structured and Unstructured, Journal of Consulting Psychology, 26, 44-49.

Lessler, K. 1964. Cultural and Freudian Dimensions of Sexual Symbols, Journal of Consulting Psychology, 28, 46-53.

Levy, L. H. 1954. Sexual Symbolism: - A Validity Study, Journal of Consulting Psychology, 18, 43-46. 
Messick, S. J. 1957. Metric Properties of the Semantic Differential, Educational and Psychological Measurement, 17, 200-206.

Moss, C. S. 1961. Experimental Paradigms for the Hypnotic Investigation of Dream Symbolism, Journal of Clinical and Experimental Hypnosis, 9 , 105-117.

Moss, C. S. 1970. Dreams, Images, and Fantasy: A Semantic Differential Casebook, Urbina: University of Illinois Press.

Osgood, E. E. 1962. Studies on the Generality of Affective Meaning Systems, American Psychologist, 17, 10-28.

Osgood, E. E., \& Lauria, A. 1954. A Blind Analysis of a Case of Multiple Personality Using the Semantic Differential, Journal of Abnormal and Social Psychology, 49, 579-591.

Osgood, E. E., Suci, G. J., \& Tannenbaum, P. H. 1957. The Measurement of Meaning, Urbina: University of Illinois Press.

Osgood, E. E., Ware, E. E., \& Morris, E. 1961. Analysis of the Connotative Meanings of a Variety of Human Values as Expressed by American College Students, Journal of Abnormal and Social Psychology, 62, 62-73.

Pope, B., \& Bare. E. E. 1961. A Semantic study of Selected Rorschach Responses, American Psychologist, 16, 392 (abstract).

Presley, A. S. 1969. Concept-Scale Interaction in the Semantic Differential and Its Implications for Factor Scores, British Journal of Psychology, 60, 109-113.

Rychlak, J. F. 1959. Forced Association, Symbolism and Rorschach Constructs, Journal of Consulting Psychology, 23, 455-460.

Schonbar, R. A., \& Davitz, J. R. 1960. The Connotative Meaning of Sexual Symbols. Journal of Consulting Psychology, 24, 483-487.

Starer, E. 1955. Cultural Symbolism: A Validity Study, Journal of Consulting Psychology, 19, 453-454.

Stennett, R. G., \& Thurlow, M. 1958. Cultural Symbolism: The Age Variable, Journal of Consulting Psychology, 22, 496.

Swartley, w. 1965. Initiated Symbol Projection, In Assagiolia, R. Psychosynthesis, New York: Viking Compass.

Triandis, H. C., \& Osgood, E. E. 1958. A Comparative Factoral Analysis of Semantic Structures in Monolingual Greek and American College Students, Journal of Abnormal and Social Psychology, 57, 187-196. 
Van den Berg, J. H. 1962. An Existential Explanation of the Guided Daydream in Psychotherapy, Review of Existential Psychology and Psychiatry, 2, 5-35.

Winter, w. D., \& Prescott, J. W. 1957. A cross validation of Starrer's Test of Cultural Symbolism, Journal of Consulting Psychology, 21,22 .

Worthy, M., \& Craddick, R. A. 1969. Semantic Differential Investigation of Sexually Symbolic Concepts, Journal of Projective Techniques and Personality Assessment, 33, 78-80. 
APPENDIX 
TABLE VII

POPULAR CONNOTATIONS OF SYMBOLS AND REFERENTS FOR MAIE AND FEMAIE SS

ASCENT M: quite valuable and fast; slightly good, nice, beautiful, pleasant, healthy, strong, large and active

F: quite beautiful, active and sharp; slightly good, nice, pleasant, clean, valuable, healthy and strong

M \& F: quite valuable and active; slightly good, nice, beautiful, pleasant, healthy, strong, fast and sharp

CoNscious $M$ : quite good, nice, beautiful, pleasant, valuable, healthy, strong, fast, active and sharp; slightly clean and large

$F$ : quite pleasant, valuable, healthy, active and sharp; slightly good, nice, beautiful, strong and fast

M \& F : quite good, nice, pleasant, valuable, healthy, strong and active; slightly beautiful, clean, fast and sharp

COW

M: quite good, valuable, healthy, strong, large, heavy and feminine; slightly pleasant and slow

F: quite good, valuable, healthy, large, heavy and slow; slightly nice, pleasant; strong, rugged, passive, sharp and feminine

M \& F: quite good, valuable, healthy, strong, large, heavy, slow and feminine; slightly nice, beautiful, pleasant and dull

$\begin{array}{lll}\text { DESCENT } & M: \text { none } \\ & F: \text { slightly heavy }\end{array}$

$M$ \& F: slightly heavy

DRAGON M: quite ugly, masculine, strong, large, heavy and rugged; slightly bad, hot, unpleasant and active

F: quite strong, large, heavy, rugged, active, hot and masculine; slightly unpleasant

M \& F: quite strong, large, rugged, active and masculine; slightly hot, ugly and unpleasant

ELEPHANT $M$ : very strong, large and heavy; quite valuable, healthy, rugged and masculine; slightly good and slow

F: very strong, large, and heavy; quite valuable, healthy, rugged, slow and dull; slightly good, nice, pleasant and masculine

FATHER M: quite good, nice, pleasant, clean, valuable, healthy, strong, large, heavy, rugged, fast, active, sharp and masculine 
F: very masculine; quite good, nice, clean, valuable, healthy and strong; slightly beautiful, pleasant, heavy, rugged and sharp

M \& F: very masculine; quite good, nice, clean, valuable, healthy, strong and rugged; slightly beautiful, pleasant, large, heavy, fast, active and sharp

HOUSE M: quite good, nice, beautiful, pleasant, clean, valuable, strong and large; slightly healthy and heavy

F: quite good, nice, pleasant and valuable; slightly beautiful, clean, strong, large and heavy

M \& F: quite good, nice, beautiful, pleasant, clean and valuable; slightly healthy, strong, large and heavy

ME

M: very clean; quite good, nice, valuable, healthy, strong, large, fast, active, sharp and masculine; slightly beautiful, pleasant, rugged and hot

F: quite good, nice, pleasant, clean, valuable, healthy and feminine; slightly beautiful, strong, active and sharp

M \& F: quite good, nice, clean, valuable, healthy, active, and sharp; slightly beautiful, pleasant, strong and fast

MOTHER M: quite good, nice, beautiful, pleasant, clean, valuable and feminine; slightly healthy, fast, active and sharp

F: quite good, nice, beautiful, pleasant, clean, valuable, healthy, active and feminine; slightly strong, fast and sharp

M \& F: quite good, nice, beautiful, pleasant, clean, valuable, healthy, active and feminine; slightly fast and sharp

PROHIBITIONS

$M$ : none

F: slightly unpleasant

M \& F: slightly unpleasant

SWORD: $M$ : very sharp; quite strong, rugged, fast and masculine; slightly valuable, active, large and cold

F: very sharp; quite strong, fast and cold; slightly valuable, large and masculine

$M \& F$ : very sharp; quite strong, fast and masculine; slightly valuable, large, rugged, active and cold

UNCONSCIOUS:

$M$ : none

F: quite passive; slightly sick

$M \& F:$ slightly passive

VASE M: quite nice, beautiful, pleasant, clean, valuable and delicate; slightl good, light and feminine

F: quite nice, beautiful, pleasant, and delicate; slightly. 
good, clean, valuable, and feminine

M \& F: quite nice, beautiful, pleasant, valuable, and delicate; slightly good, clean, light and feminine

WITCH. M: very feminine; quite bad, awful, ugly, dirty and cold; slightly worthless, sick, strong and active

F: quite bad, ugly, unpleasant, active and feminine; slightly strong, fast and sharp

M \& F: quite bad, ugly, unpleasant, active and feminine; slightly awful, dirty, strong and sharp

WIZARD M: quite strong, active, sharp and masculine; slightly good, healthy and fast

F: quite active and sharp; slightly strong, fast and masculine

M \& F: quite active, sharp, masculine; slightly good, strong and fast 
POPULAR OR NORMATIVE $D^{2}$ BETWEEN SYMBOLS AND REFERENTS FOR MALE SS

\begin{tabular}{|c|c|c|c|c|c|c|c|c|c|c|c|c|c|c|c|}
\hline ASCENT & 0 & & & & & & & & & & & & & & \\
\hline conscrous & 6.56 & & & & & & & & & & - & & & & \\
\hline Cow & 30.83 & 38.82 & & & . & & & & & & & & & & \\
\hline DESCENT & 14.92 & 33.99 & 24.58 & & . & & & & & & & & & & \\
\hline DRAGON & 52.70 & 81.03 & 68.35 & 39.85 & & & & & & & & & & & \\
\hline EIEEPHANT & 37.13 & 51.84 & -5.68 & 35.92 & 35.26 & & & . & & & & & & & \\
\hline FATHER & 12.33 & 15.05 & 46.78 & 38.87 & 59.05 & 32.85 & & & & & & & & & \\
\hline HOUSE & 11.01 & 10.40 & 18.45 & 29.35 & 77.99 & 34.22 & 14.67 & & & & & . & & & \\
\hline ME & 10.78 & 9.61 & 53.60 & 44.28 & 71.13 & 47.81 & 4.69 & 16.04 & & & . & & & . & \\
\hline MOTHER & 19.01 & 16.30 & .39 .97 & 32.52 & 109.93 & 86.25 & 47.36 & 21.66 & 38.48 & & & & . & & \\
\hline PROHIBITIONS & 32.50 & 60.59 & 43.03 & 7.64 & 26.94 & 47.37 & 60.67 & 55.72 & 64.92 & 58.41 & & & & & \\
\hline SWORD & 18.59 & 32.51 & 62.36 & 29.01 & 35.47 & 43.02 & 20.65 & 38.45 & 25.37 & 60.80 & 34.15 & & & & \\
\hline UNCONSCIOUS & 33.62 & 58.04 & $32: 69$ & 6.11 & 49.22 & 52.13 & 65.40 & 48.53 & 70.66 & 49.73 & 7.39 & 46.01 & & & \\
\hline VASE & 27.33 & 32.21 & 39.61 & 23.75 & 111.80 & 84.85 & 63.04 & 32.61 & 56.05 & 14.50 & 45.31 & 63.49 & 28.15 & & \\
\hline WITCH & 85.21 & .120 .53 & 100.50 & 48.19 & 55.90 & 113.47 & 132.68 & 127.02 & 138.66 & 103.40 & 30.56 & 71.68 & 46.15 & 94.80 & \\
\hline WIZARD & 5.72 & 13.40 & 45.45 & 19.30 & 37.78 & 35.45 & 10.73 & 22.58 & 11.20 & 36.20 & 30.32 & 9.58 & 39.97 & 45.24 & 81.37 \\
\hline , & $\underset{8}{5}$ & $\begin{array}{c}5 \\
0^{0} \\
0 \\
0 \\
0 \\
0 \\
0\end{array}$ & $\hat{\theta}$ & 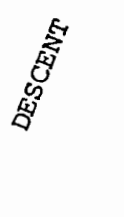 & 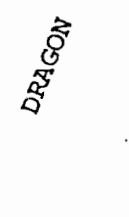 & 氛 & $\underset{4}{\stackrel{5}{G}}$ & $\stackrel{5}{5}^{5}$ & si & 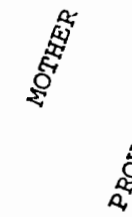 & 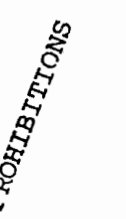 & 今. & $\overbrace{}^{\infty}$ & $\begin{array}{c}5 \\
5 \\
5\end{array}$ & 占 \\
\hline
\end{tabular}


TABLE IX

POPULAR OR NORMATIVE $D^{2}$ BETWEEN SYMBOLS AND REFERENTS FOR MALE SS SUMMARY OF DISTANCES FROM SYMBOLS

\begin{tabular}{|c|c|c|c|c|c|c|c|c|}
\hline & & & & & . & & & $D^{2}$ \\
\hline . & lst & 2nd & $3 \mathrm{rd}$ & 4th & $\underline{5 t h}$ & 6th & 7th & RANGE \\
\hline ASCENT & $\begin{array}{r}5.72 \\
\text { wizard }\end{array}$ & $\begin{array}{c}6.56 \\
\text { Conscious * }\end{array}$ & 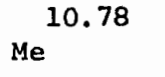 & $\begin{array}{l}11.01 \\
\text { House }\end{array}$ & $\begin{array}{l}12.33 \\
\text { Father }\end{array}$ & $\begin{array}{r}14.92 \\
\text { Descent }\end{array}$ & $\begin{array}{l}18.59 \\
\text { Sword }\end{array}$ & 79.49 \\
\hline COW & $\begin{array}{l}18.45 \\
\text { House }\end{array}$ & $\begin{array}{c}24.58 \\
\text { Descent }\end{array}$ & $\begin{array}{c}25.68 \\
\text { Elephant }\end{array}$ & $\begin{array}{l}30.83 \\
\text { Ascent }\end{array}$ & $\begin{array}{c}32.69 \\
\text { Unconscious }\end{array}$ & $\begin{array}{l}38.82 \\
\text { Conscious }\end{array}$ & $\begin{array}{l}39.61 \\
\text { Vase }\end{array}$ & 82.05 \\
\hline DESCENT & $\begin{array}{c}6.11 \\
\text { Unconscious } \\
\end{array}$ & $\begin{array}{l}7.64 \\
\text { Prohibitions }\end{array}$ & $\begin{array}{l}14.92 \\
\text { Ascent }\end{array}$ & $\begin{array}{l}19.30 \\
\text { wizard }\end{array}$ & $\begin{array}{l}23.75 \\
\text { Vase }\end{array}$ & $\begin{array}{l}24.58 \\
\text { Cow }\end{array}$ & $\begin{array}{l}29.01 \\
\text { Sword }\end{array}$ & 42.08 \\
\hline DRAGON & $\begin{array}{c}26.94 \\
\text { Prohibitions }\end{array}$ & $\begin{array}{l}35.26 \\
\text { Elephant }\end{array}$ & $\begin{array}{l}35.47 \\
\text { Sword }\end{array}$ & $\begin{array}{l}37.78 \\
\text { Wizard }\end{array}$ & $\begin{array}{r}39.85 \\
\text { Descent }\end{array}$ & $\begin{array}{c}49.22 \\
\text { Unconscious }\end{array}$ & $\begin{array}{l}52.70 \\
\text { Ascent }\end{array}$ & 86.86 \\
\hline ELEPHANT & $\begin{array}{l}25.68 \\
\text { Cow }\end{array}$ & $\begin{array}{r}32.85 \\
\text { Father } \\
\end{array}$ & $\begin{array}{l}34.22 \\
\text { House }\end{array}$ & $\begin{array}{l}35.26 \\
\text { Dragon }\end{array}$ & $\begin{array}{l}35.45 \\
\text { Wizard }\end{array}$ & $\begin{array}{r}39.92 \\
\text { Descent }\end{array}$ & $\begin{array}{l}37.13 \\
\text { Ascent }\end{array}$ & 87.79 \\
\hline HOUSE & $\begin{array}{l}10.40 \\
\text { Conscious }\end{array}$ & $\begin{array}{r}11.01 \\
\text { Ascent }\end{array}$ & $\begin{array}{l}14.67 \\
\text { Father }\end{array}$ & $\underline{\mathrm{Me}}^{16.04}$ & Cow & $\begin{array}{l}21.66 \\
\text { Mother }\end{array}$ & $\begin{array}{l}22.58 \\
\text { Wizard }\end{array}$ & 116.62 \\
\hline SWORD & $\begin{array}{r}9.88 \\
\text { Wizard }\end{array}$ & $\begin{array}{r}18.59 \\
\text { Ascent }\end{array}$ & $\begin{array}{l}20.65 \\
\text { Father }\end{array}$ & $\mathrm{Me}^{25.37}$ & $\begin{array}{r}29.01 \\
\text { Descent }\end{array}$ & $\begin{array}{c}32.51 \\
\text { Conscious }\end{array}$ & $\begin{array}{l}34.15 \\
\text { Prohibitions }\end{array}$ & 61.80 \\
\hline VASE & $\begin{array}{r}14.50 \\
\text { Mother }\end{array}$ & $\begin{array}{c}23.75 \\
\text { Descent }\end{array}$ & $\begin{array}{l}27.33 \\
\text { Ascent }\end{array}$ & $\begin{array}{l}28.25 \\
\text { Unconscious }\end{array}$ & $\begin{array}{c}32.21 \\
\text { Conscious }\end{array}$ & $\begin{array}{l}39.61 \\
\text { House }\end{array}$ & $\begin{array}{l}45.24 \\
\text { wizard }\end{array}$ & 97.30 \\
\hline WITCH & $\begin{array}{l}30.56 \\
\text { Prohibitions }\end{array}$ & $\begin{array}{l}46.15 \\
\text { Unconscious }\end{array}$ & $\begin{array}{r}48.19 \\
\text { Descent }\end{array}$ & $\begin{array}{c}55.90 \\
\text { Dragon }\end{array}$ & $\begin{array}{l}71: 68 \\
\text { Sword }\end{array}$ & $\begin{array}{l}81.37 \\
\text { Wizard }\end{array}$ & $\begin{array}{l}85.21 \\
\text { Ascent }\end{array}$ & 108.10 \\
\hline WIZARD & $\begin{array}{r}5.72 \\
\text { Ascent }\end{array}$ & $\begin{array}{l}9.58 \\
\text { Sword }\end{array}$ & $\begin{array}{l}10.73 \\
\text { Eather }\end{array}$ & $\mathrm{Me}^{11.20}$ & $\begin{array}{c}13.40 \\
\text { Conscious }\end{array}$ & $\begin{array}{r}19.30 \\
\text { Descent }\end{array}$ & $\begin{array}{l}22.58 \\
\text { House }\end{array}$ & 75.65 \\
\hline
\end{tabular}

*underlined concepts represent the theoretical referent for the symhol on the left. If no concept is underlined in a given row, the theoretical referent did not appear in the first seven closest distances. 
TABLE $\mathrm{x}$

POPULAR OR NORMATIVE $\mathrm{D}^{2}$ BETWEEN SYMBOLS AND REFERENTS FOR FEMALE SS

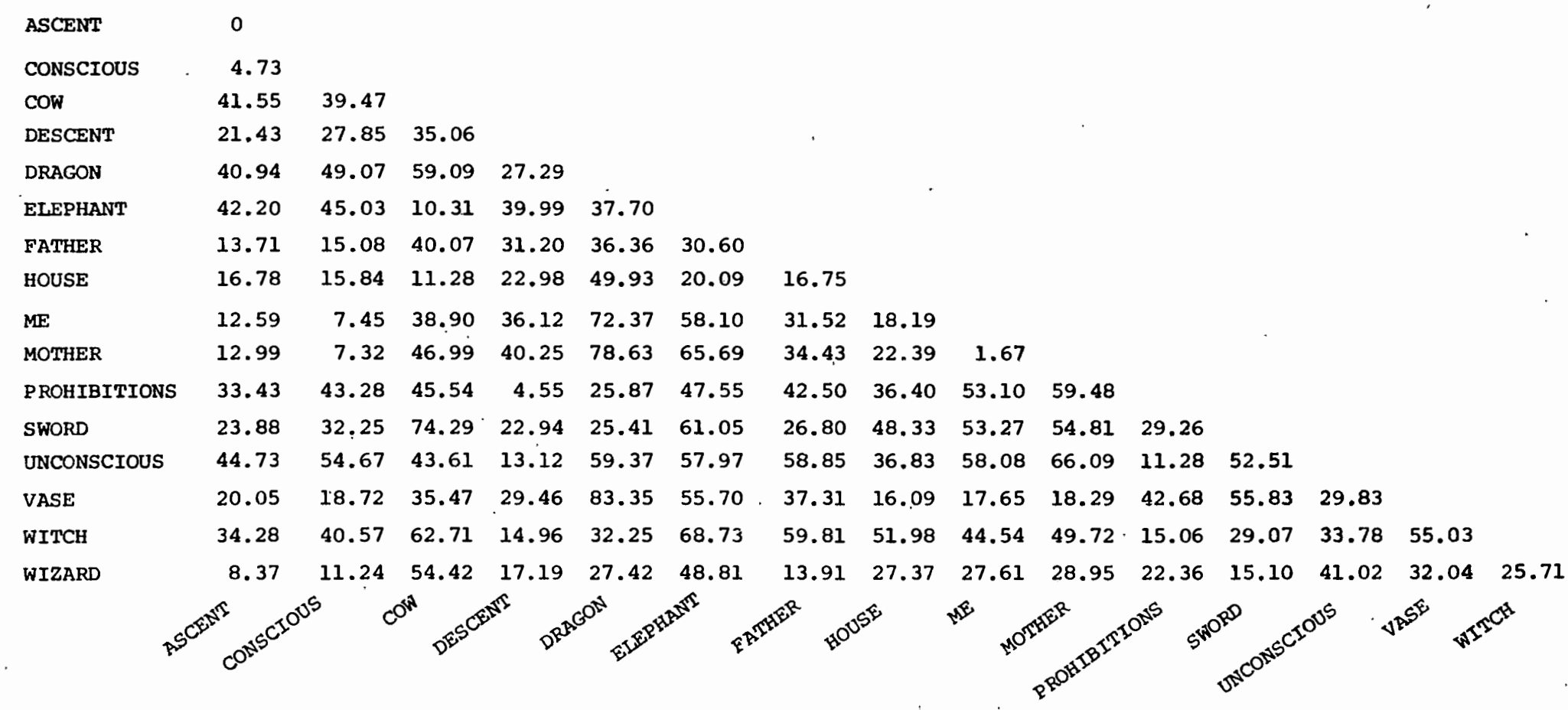


TABLE XI

POPUI AAR OR NORMATIVE $D^{2}$ BETWEEN SYMBOLS AND REFERENTS FOR FEMALE SS SUMMARY OF DISTANCES FROM SYMBOLS

\begin{tabular}{|c|c|c|c|c|c|c|c|c|}
\hline & lst & 2nd & $3 \mathrm{rd}$ & 4th & 5th & 6 th & 7th & $\begin{array}{c}\mathrm{D}^{2} \\
\text { RANGE } \\
\end{array}$ \\
\hline ASCENT & $\begin{array}{c}4.30 \\
\text { Conscious * }\end{array}$ & $\begin{array}{l}8.37 \\
\text { Wizara }\end{array}$ & $M e^{12.59}$ & $\begin{array}{l}12.99 \\
\text { Mother }\end{array}$ & $\begin{array}{l}13.71 \\
\text { Father }\end{array}$ & $\begin{array}{l}16.78 \\
\text { House }\end{array}$ & $\begin{array}{l}20.05 \\
\text { Vase }\end{array}$ & 40.00 \\
\hline COW & $\begin{array}{c}10.31 \\
\text { Elephant }\end{array}$ & $\begin{array}{l}11.28 \\
\text { Houge }\end{array}$ & $\begin{array}{l}35.06 \\
\text { Descent }\end{array}$ & $\begin{array}{l}35.47 \\
\text { Vase }\end{array}$ & $\mathrm{Me}^{38.90}$ & $\begin{array}{c}39.47 \\
\text { Conscious }\end{array}$ & $\begin{array}{l}40.07 \\
\text { Father }\end{array}$ & 63.98 \\
\hline DESCENT & $\begin{array}{l}4.55 \\
\text { Prohibitions }\end{array}$ & $\begin{array}{c}13.12 \\
\text { Unconscious } \\
\end{array}$ & $\begin{array}{l}14.96 \\
\text { witch }\end{array}$ & $\begin{array}{l}17.19 \\
\text { Wizard }\end{array}$ & $\begin{array}{l}21.43 \\
\text { Ascent }\end{array}$ & $\begin{array}{l}22.94 \\
\text { Sword }\end{array}$ & $\begin{array}{l}22.98 \\
\text { House }\end{array}$ & 35.70 \\
\hline DRAGON & $\begin{array}{l}25.41 \\
\text { Sword }\end{array}$ & $\begin{array}{c}25.81 \\
\text { Prohibitions } \\
\end{array}$ & $\begin{array}{r}27.29 \\
\text { Descent }\end{array}$ & $\begin{array}{l}27.42 \\
\text { Wizard }\end{array}$ & $\begin{array}{l}32.25 \\
\text { witch }\end{array}$ & $\begin{array}{l}36.36 \\
\text { Father }\end{array}$ & $\begin{array}{c}37.70 \\
\text { Elephant }\end{array}$ & 57.94 \\
\hline ELEPHANT & $\begin{array}{l}10.31 \\
\text { Cow }\end{array}$ & $\begin{array}{l}20.09 \\
\text { House }\end{array}$ & $\begin{array}{r}30.60 \\
\text { Father }\end{array}$ & $\begin{array}{l}37.70 \\
\text { Dragon }\end{array}$ & $\begin{array}{r}39.99 \\
\text { Descent }\end{array}$ & $\begin{array}{l}42.20 \\
\text { Ascent }\end{array}$ & $\begin{array}{l}45.03 \\
\text { Cow }\end{array}$ & 58.42 \\
\hline HOUSE & $\begin{array}{l}11.28 \\
\text { Cow }\end{array}$ & $\begin{array}{c}15.84 \\
\text { Conscious }\end{array}$ & $\begin{array}{l}16.09 \\
\text { Vase }\end{array}$ & $\begin{array}{l}16.75 \\
\text { Father }\end{array}$ & $\begin{array}{l}16.78 \\
\text { Ascent }\end{array}$ & $\underline{\mathrm{Me}}=$ & $\begin{array}{c}20.09 \\
\text { Elephant }\end{array}$ & 40.70 \\
\hline SWORD & $\begin{array}{l}15.10 \\
\text { Wizard }\end{array}$ & $\begin{array}{r}22.94 \\
\text { Descent }\end{array}$ & $\begin{array}{l}23.88 \\
\text { Ascent }\end{array}$ & $\begin{array}{l}25.41 \\
\text { Dragon }\end{array}$ & $\begin{array}{r}26.80 \\
\text { Father } \\
\end{array}$ & $\begin{array}{l}29.07 \\
\text { Witch }\end{array}$ & $\begin{array}{l}29.26 \\
\text { Prohibitions }\end{array}$ & 59.19 \\
\hline VASE & $\begin{array}{l}16.09 \\
\text { House }\end{array}$ & $\underline{\mathrm{Me}}$ & $\begin{array}{r}18.29 \\
\text { Mother }\end{array}$ & $\begin{array}{c}18.72 \\
\text { Conscious }\end{array}$ & $\begin{array}{l}20.05 \\
\text { Ascent }\end{array}$ & $\begin{array}{r}29.46 \\
\text { Descent }\end{array}$ & $\begin{array}{c}29.83 \\
\text { Unconscious }\end{array}$ & 67.26 \\
\hline WITCH . & $\begin{array}{r}14.96 \\
\text { Descent }\end{array}$ & $\begin{array}{l}15.06 \\
\text { Prohibitions }\end{array}$ & $\begin{array}{l}25.71 \\
\text { wizard }\end{array}$ & $\begin{array}{l}29.07 \\
\text { Sword }\end{array}$ & $\begin{array}{l}32.25 \\
\text { Dragon }\end{array}$ & $\begin{array}{c}33.78 \\
\text { Unconscious }\end{array}$ & $\begin{array}{l}34.28 \\
\text { Ascent }\end{array}$ & 53.77 \\
\hline WIZARD & $\begin{array}{l}8.37 \\
\text { Ascent }\end{array}$ & $\begin{array}{c}11.24 \\
\text { Conscious }\end{array}$ & $\begin{array}{r}13.91 \\
\text { Father } \\
\end{array}$ & $\begin{array}{l}15.10 \\
\text { Sword }\end{array}$ & $\begin{array}{r}17.19 \\
\text { Descent }\end{array}$ & $\begin{array}{l}22.36 \\
\text { Prohibitions }\end{array}$ & $\begin{array}{l}25.71 \\
\text { Witch }\end{array}$ & 40.44 \\
\hline - & $\begin{array}{l}\text { *underlined } \\
\text { concept is } \\
\text { seven close }\end{array}$ & Ined 11 & & $\tau$ & re & $\begin{array}{l}\text { symbe } \\
\text { did }\end{array}$ & $\begin{array}{l}\text { left. Tf no } \\
\text { in the first }\end{array}$ & \\
\hline
\end{tabular}


TABIE XII

POPULAR OR NORMATIVE $\mathrm{D}^{2}$ BETWEEN SYMBOLS AND REFERENTS FOR FEMALE AND MALE Ss

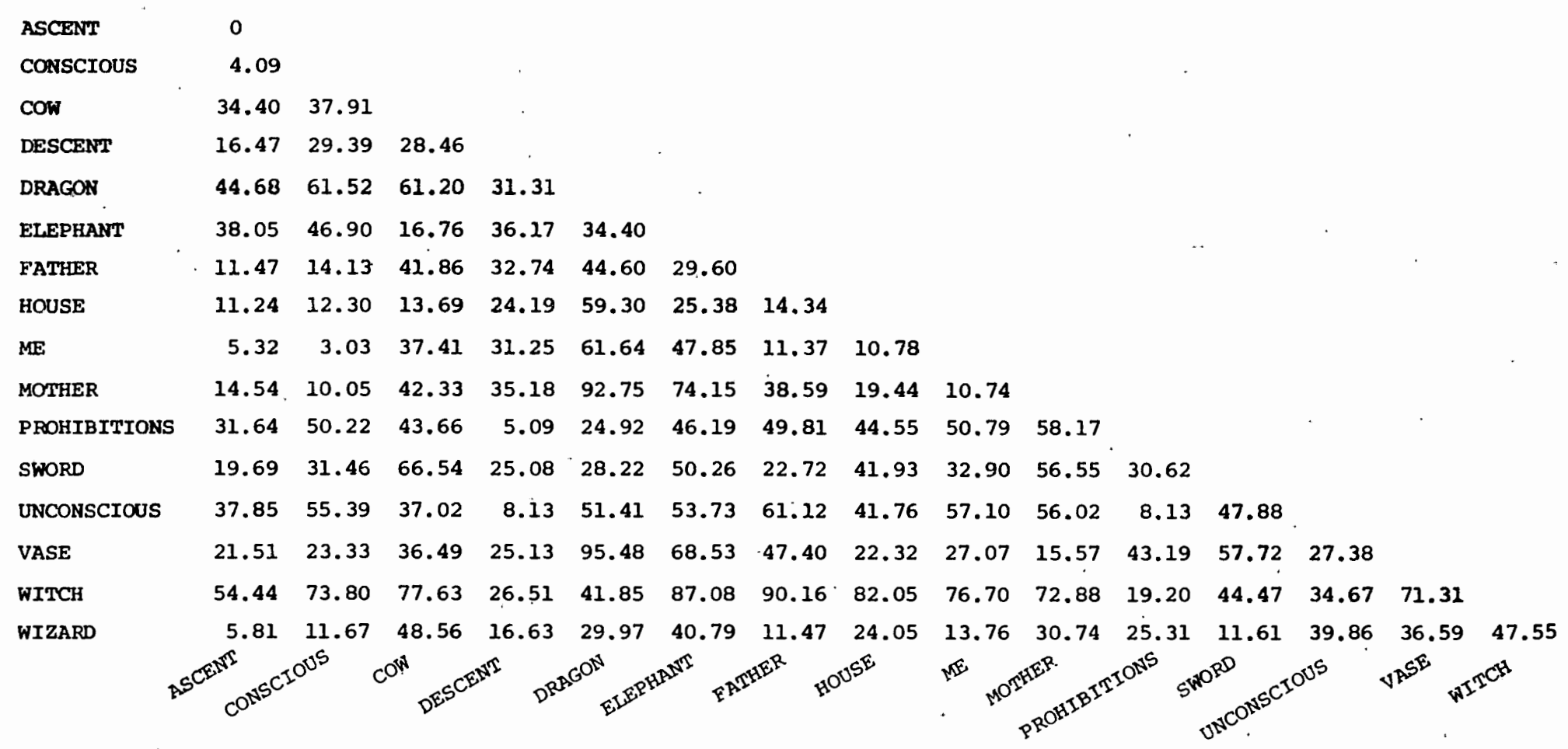


TABLE XIII

POPULAR OR NORMATIVE $\mathrm{D}^{2}$ BETWEEN SYMBOLS AND REFERENTS FOR MALE AND FEMALE SS SUMMARY OF DISTANCES FROM SYMBOLS

\begin{tabular}{|c|c|c|c|c|c|c|c|c|}
\hline & & & & & & & & $D^{2}$ \\
\hline & Ist & 2nd & $3 r d$ & 4th & 5th & 6th & 7th & RANGE \\
\hline ASCENT & $\begin{array}{c}4.09 \\
\text { Conscious * }\end{array}$ & 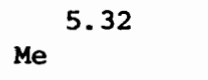 & $\begin{array}{l}5.81 \\
\text { Wizard }\end{array}$ & $\begin{array}{l}11.24 \\
\text { House }\end{array}$ & $\begin{array}{l}11.47 \\
\text { Father }\end{array}$ & $\begin{array}{l}14.54 \\
\text { Mother }\end{array}$ & $\begin{array}{r}16.47 \\
\text { Descent }\end{array}$ & 50.35 \\
\hline CON & $\begin{array}{l}13.69 \\
\text { House }\end{array}$ & $\begin{array}{l}16.76 \\
\text { Elephant }\end{array}$ & $\begin{array}{r}28.46 \\
\text { Descent }\end{array}$ & $\begin{array}{l}34.40 \\
\text { Ascent }\end{array}$ & $\begin{array}{l}36.49 \\
\text { Vase }\end{array}$ & $\begin{array}{c}37.02 \\
\text { Unconscious }\end{array}$ & $\mathrm{Me}^{37.41}$ & 63.94 \\
\hline DESCENT & $\begin{array}{c}5.09 \\
\text { Prohibitions }\end{array}$ & $\begin{array}{c}8.13 \\
\text { Unconscious } \\
\end{array}$ & $\begin{array}{l}16.47 \\
\text { Ascent }\end{array}$ & $\begin{array}{l}16.63 \\
\text { Wizard }\end{array}$ & $\begin{array}{l}24.19 \\
\text { House }\end{array}$ & $\begin{array}{l}25.08 \\
\text { Sword }\end{array}$ & $\begin{array}{l}25.13 \\
\text { Vase }\end{array}$ & 31.08 \\
\hline DRAGON & $\begin{array}{c}24.92 \\
\text { Prohibitions } \\
\end{array}$ & ${ }_{\text {Sword }}^{28.22}$ & $\begin{array}{l}29.97 \\
\text { Wizard }\end{array}$ & $\begin{array}{r}31.31 \\
\text { Descent }\end{array}$ & $\begin{array}{c}34.40 \\
\text { Elephant }\end{array}$ & $\begin{array}{l}41.85 \\
\text { Witch }\end{array}$ & $\begin{array}{l}44.60 \\
\text { Father }\end{array}$ & 70.56 \\
\hline ELEPHANT & $\begin{array}{l}16.76 \\
\text { Cow }\end{array}$ & $\begin{array}{l}25.38 \\
\text { House }\end{array}$ & $\begin{array}{r}29.60 \\
\text { Father } \\
\end{array}$ & $\begin{array}{l}34.40 \\
\text { Dragon }\end{array}$ & $\begin{array}{r}36.17 \\
\text { Descent }\end{array}$ & $\begin{array}{l}38.05 \\
\text { Ascent }\end{array}$ & $\begin{array}{l}40.79 \\
\text { wizard }\end{array}$ & 70.32 \\
\hline WIZARD & $\begin{array}{l}5.81 \\
\text { Ascent }\end{array}$ & $\begin{array}{l}11.47 \\
\text { Father }\end{array}$ & $\begin{array}{l}11.62 \\
\text { Sword }\end{array}$ & $\begin{array}{c}11.67 \\
\text { Conscious }\end{array}$ & $\mathrm{Me}^{13.76}$ & $\begin{array}{r}16.63 \\
\text { Descent }\end{array}$ & $\begin{array}{l}24.05 \\
\text { House }\end{array}$ & 42.75 \\
\hline HOUSE & $\underline{\mathrm{Me}}^{10.78}$. & $\begin{array}{l}11.24 \\
\text { Ascent }\end{array}$ & $\begin{array}{c}12.30 \\
\text { Conscious }\end{array}$ & $\begin{array}{l}13.69 \\
\text { Cow }\end{array}$ & $\begin{array}{l}14.34 \\
\text { Father }\end{array}$ & $\begin{array}{l}19.44 \\
\text { Mother }\end{array}$ & $\begin{array}{l}22.32 \\
\text { Vase }\end{array}$ & 71.27 \\
\hline SWORD & $\begin{array}{l}11.61 \\
\text { Wizard }\end{array}$ & $\begin{array}{l}19.69 \\
\text { Ascent }\end{array}$ & $\begin{array}{l}22.72 \\
\text { Father } \\
\end{array}$ & $\begin{array}{r}25.08 \\
\text { Descent }\end{array}$ & $\begin{array}{c}28.22 \\
\text { Dragon }\end{array}$ & $\begin{array}{l}30.62 \\
\text { Prohibitions }\end{array}$ & $\begin{array}{c}31.46 \\
\text { Conscious }\end{array}$ & 54.93 \\
\hline VASE & $\begin{array}{l}15.57 \\
\text { Mother } \\
\end{array}$ & $\begin{array}{l}21.51 \\
\text { Ascent }\end{array}$ & $\begin{array}{l}22.32 \\
\text { House. }\end{array}$ & $\begin{array}{c}23.33 \\
\text { Conscious }\end{array}$ & $\begin{array}{r}25.13 \\
\text { Descent }\end{array}$ & $M e^{27.07}$ & $\begin{array}{c}27.38 \\
\text { Unconscious }\end{array}$ & 79.91 \\
\hline WITCH & $\begin{array}{c}19.20 \\
\text { Prohibitions }\end{array}$ & $\begin{array}{r}26.51 \\
\text { Descent }\end{array}$ & $\begin{array}{c}34.67 \\
\text { Unconscious }\end{array}$ & $\begin{array}{l}44.47 \\
\text { Sword }\end{array}$ & $\begin{array}{l}47.55 \\
. \text { Wizard }\end{array}$ & $\begin{array}{l}54.44 \\
\text { Ascent }\end{array}$ & $\begin{array}{l}71.31 \\
\text { Vase }\end{array}$ & 70.96 \\
\hline
\end{tabular}

*underlined concepts represent the theoretical referent for the symbol on the left. If no concept is underlined in a given row, the theoretical referent did not appear in the first seven closest distances. 


\section{TABLE XIV}

AVERAGE OF INDIVIDUALS $D^{2}$ RELATTONSHIPS BETWEEN SYMBOIS AND REFERENTS FOR MALE SS

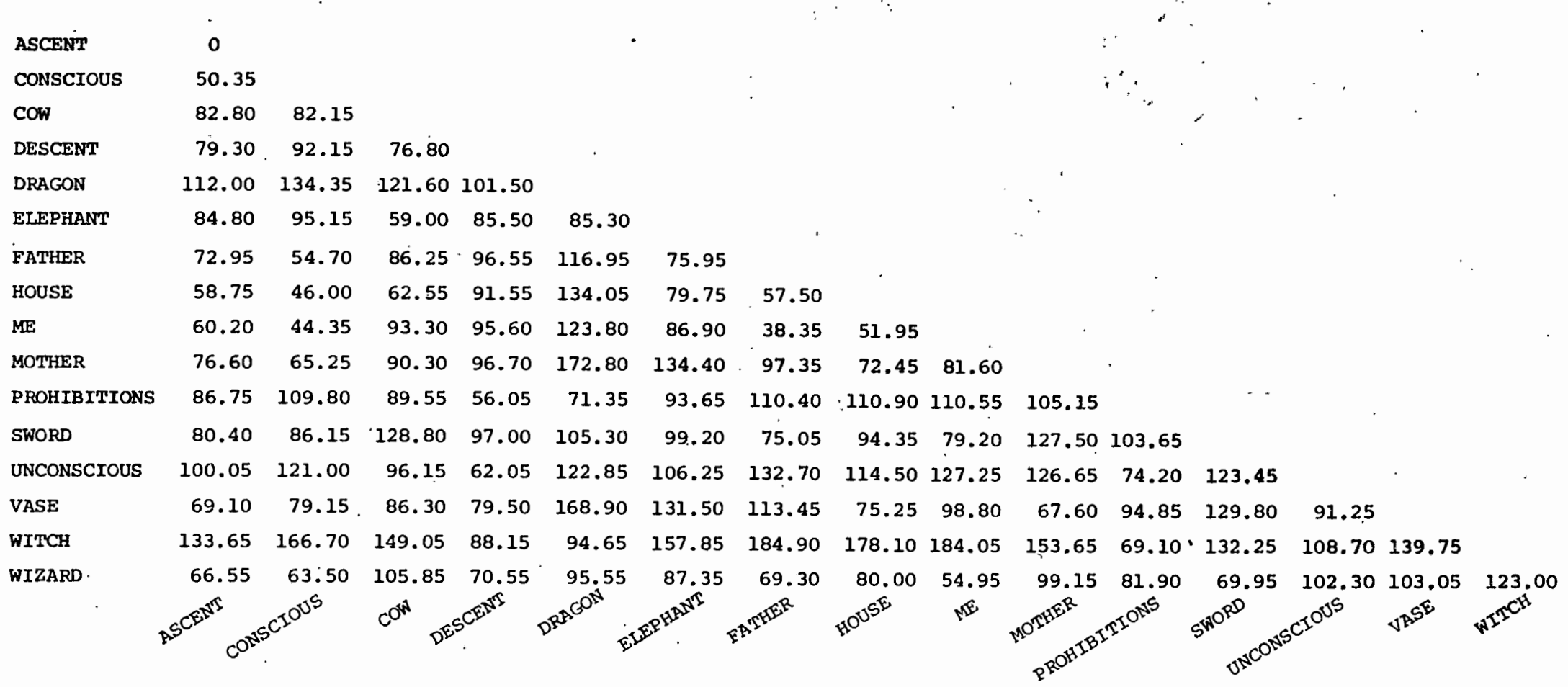


TABLE XV

AVERAGE OF INDTVIDUALS $D^{2}$ RELATIONSHIPS BETWEEN SYMBOLS AND REFERENTS FOR MALE SS

SUMMARY OF DISTANCES FROM SYMBOLS

\begin{tabular}{|c|c|c|c|c|c|c|c|c|}
\hline & 1st & 2nd & $3 r d$ & 4th & 5th & 6th & 7th & $\begin{array}{c}\mathrm{D}^{2} \\
\text { RANGE } \\
\end{array}$ \\
\hline ASCENT & $\begin{array}{c}50.35 ! \\
\text { Conscious * }\end{array}$ & $\begin{array}{l}58.75 \\
\text { House }\end{array}$ & 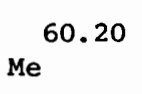 & $\begin{array}{l}66.55 \\
\text { Wizard }\end{array}$ & $\begin{array}{l}69.10 \\
\text { Vase }\end{array}$ & $\begin{array}{l}72.95 \\
\text { Father }\end{array}$ & $\begin{array}{l}76.60 \\
\text { Mother }\end{array}$ & 83.30 \\
\hline cow & $\begin{array}{l}59.00 \\
\text { Elephant }\end{array}$ & $\begin{array}{l}62.55 \\
\text { House }\end{array}$ & $\begin{array}{r}76.80 \\
\text { Descent }\end{array}$ & $\begin{array}{c}82.15 \\
\text { Conscious }\end{array}$ & $\begin{array}{l}82.80 \\
\text { Ascent }\end{array}$ & $\begin{array}{l}86.25 \\
\text { Father }\end{array}$ & $\begin{array}{l}86.30 \\
\text { Vase }\end{array}$ & 110.65 \\
\hline DESCENT. & $\begin{array}{l}56.05 \\
\text { Prnhibitions }\end{array}$ & $\begin{array}{c}62.05 \\
\text { Unconscious } \\
\end{array}$ & $\begin{array}{l}70.55 \\
\text { wizard }\end{array}$ & $\begin{array}{l}76.80 \\
\text { Cow }\end{array}$ & $\begin{array}{l}79.30 \\
\text { Ascent }\end{array}$ & $\begin{array}{l}79.50 \\
\text { Vase }\end{array}$ & $\begin{array}{l}85.50 \\
\text { Dragon }\end{array}$ & 78.30 \\
\hline DRAGON & $\begin{array}{c}71.35 \\
\text { Prohibitions } \\
\end{array}$ & $\begin{array}{c}85.30 \\
\text { Elephant }\end{array}$ & $\begin{array}{l}94.65 \\
\text { Witch }\end{array}$ & $\begin{array}{l}95.55 \\
\text { Wizard }\end{array}$ & $\begin{array}{r}101.50 \\
\text { Descent }\end{array}$ & $\begin{array}{l}105.30 \\
\text { Sword }\end{array}$ & $\begin{array}{l}112.00 \\
\text { Ascent }\end{array}$ & 97.55 \\
\hline ELEPHANT & $\begin{array}{l}59.00 \\
\text { Cow }\end{array}$ & $\begin{array}{r}75.95 \\
\text { Father } \\
\end{array}$ & $\begin{array}{l}.79 .75 \\
\text { House }\end{array}$ & $\begin{array}{l}84.80 \\
\text { Ascent }\end{array}$ & $\begin{array}{l}85.30 \\
\text { Dragon }\end{array}$ & $\begin{array}{r}85.50 \\
\text { Descent }\end{array}$ & $\begin{array}{c}86.89 \\
M E\end{array}$ & 98.85 \\
\hline HOUSE & $\begin{array}{c}46.00 \\
\text { Conscious }\end{array}$ & $\underline{\mathrm{Me}}$ & $\begin{array}{l}57.50 \\
\text { Father }\end{array}$ & $\begin{array}{l}58.75 \\
\text { Ascent }\end{array}$ & $\begin{array}{l}62.55 \\
\text { Cow }\end{array}$ & $\begin{array}{l}72.45 \\
\text { Mother }\end{array}$ & $\begin{array}{l}75.25 \\
\text { Vase }\end{array}$ & 132.10 \\
\hline SWORD & $\begin{array}{l}69.95 \\
\text { Wizard }\end{array}$ & $\begin{array}{l}75.05 \\
\text { Father }\end{array}$ & $\mathrm{Me}^{79.20}$ & $\begin{array}{l}80.40 \\
\text { Ascent }\end{array}$ & $\begin{array}{c}86.15 \\
\text { Conscious }\end{array}$ & $\begin{array}{l}94.35 \\
\text { House }\end{array}$ & $\begin{array}{r}97.00 \\
\text { Descent }\end{array}$ & 62.30 \\
\hline VASE & $\begin{array}{r}67.60 \\
\text { Mother } \\
\end{array}$ & $\begin{array}{l}69.10 \\
\text { Ascent }\end{array}$ & $\begin{array}{l}75.25 \\
\text { House }\end{array}$ & $\begin{array}{c}79.15 \\
\text { Conscious }\end{array}$ & $\begin{array}{r}79.50 \\
\text { Descent }\end{array}$ & $\begin{array}{l}86.30 \\
\text { Cow }\end{array}$ & $\begin{array}{c}91.25 \\
\text { Unconscious }\end{array}$ & 101.30 \\
\hline WITCH & $\begin{array}{l}69.10 \\
\text { Prohibitions }\end{array}$ & $\begin{array}{r}88.15 \\
\text { Descent }\end{array}$ & $\begin{array}{l}94.65 \\
\text { Dragon }\end{array}$ & $\begin{array}{l}108.70 \\
\text { Unconscious }\end{array}$ & $\begin{array}{l}123.00 \\
\text { wizard }\end{array}$ & $\begin{array}{l}132.25 \\
\text { Sword }\end{array}$ & $\begin{array}{l}139.75 \\
\text { Vase. }\end{array}$ & 115.80 \\
\hline WIZARD & $\mathrm{Me}^{54.95}$ & $\begin{array}{c}63.50 \\
\text { Conscious }\end{array}$ & $\begin{array}{l}66.55 \\
\text { Ascent }\end{array}$ & $\begin{array}{l}69.30 \\
\text { Father }\end{array}$ & $\begin{array}{l}69.95 \\
\text { Sword }\end{array}$ & $\begin{array}{r}70.55 \\
\text { Descent }\end{array}$ & $\begin{array}{l}80.00 \\
\text { House }\end{array}$ & 68.05 \\
\hline
\end{tabular}

*underlined concepts represent the theoretical referent for the symbol on the left. If no concept is underlined in a given row, the theoretical referent did not appear in the first seven closest distances. 
TABLE XVI

AVERAGE OF INDIVIDUALS $D^{2}$ RELATIONSHIPS BETWEEN SYMBOLS AND REFERENTS FOR FEMALE SS

\begin{tabular}{|c|c|c|c|c|c|c|c|c|c|c|c|c|c|c|c|}
\hline ASCENT & 0 & & & & & & & & & & & & & & \\
\hline CONSCIOUS & 46.30 & & & & & • & & & & & & & & & \\
\hline cow & 88.95 & 84.45 & & & & & . & & . & & & & & & \\
\hline DESCENT & 87.25 & 76.75 & 92.60 & & & & & & & & & & $\cdot$ & & \\
\hline DRAGON & 98.00 & $107: 80$ & 115.85 & 89.55 & * & & & & & & & & & & \\
\hline ELEPHANT & 87.70 & 88.20 & 46.55 & 103.15 & 86.40 & & & & & & & & & & \\
\hline FATHER & 80.50 & 62.10 & 96.65 & 86.75 & 116.80 & 93.90 & & • & & & & & & & \\
\hline HOUSE & 65.35 & 66.55 & 56.20 & 74.00 & 118.15 & 75.75 & 74.05 & & & & . & & & & \\
\hline ME & 55.65 & 44.35 & 86.40 & 81.10 & 131.25 & 106.85 & 81.35 & 62.60 & & & & & & & \\
\hline MOTHER & 63.35 & 49.65 & 92.50 & 89.80 & 144.25 & 118.55 & 92.25 & 72.10 & 39.90 & & & & & & \\
\hline PROHIBITIONS & 96.00 & 92.60 & 93.95 & 37.45 & 84.30 & 105.90 & 100.70 & 89.85 & 102.55 & 110.25 & & & & & \\
\hline SWORD & 64.50 & 77.20 & 130.35 & 81.45 & 76.10 & 112.00 & 93.80 & $95: 65$ & 98.95 & 111.05 & 81.50 & & & & \\
\hline UNCONSCIOUS & 95.70 & 114.60 & 96.85 & 66.55 & 121.80 & 110.00 & 139.00 & 88.55 & 107.95 & 125.95 & 75.80 & 105.80 & & & 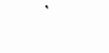 \\
\hline VASE & 66.05 & 63.15 & 85.60 & 88.00 & 147.85 & 106.85 & 96.75 & 65.70 & 52.00 & 70.60 & 109.35 & 107.75 & 88.25 & & \\
\hline WITCH & 82.95 & 86.75 & $116: 20$ & 71.90 & 77.55 & 117.85 & 127.45 & 109.20 & 92.10 & 108.60 & 67.05 & 71.35 & 90.05 & 312.70 & \\
\hline WIZARD & 55.10 & 58.50 & $\begin{array}{c}105.65 \\
\mathrm{co}^{*}\end{array}$ & 83.05 & 80.20 & 95.90 & 77.60 & 89.15 & $\begin{array}{l}86.85 \\
\text { sis }\end{array}$ & 96.45 & 88.60 & 67.00 & $\begin{array}{l}100.70 \\
5\end{array}$ & $\frac{88.85}{55^{4}}$ & ${ }^{64.05}$ \\
\hline
\end{tabular}




\section{TABLE XVII}

AVERAGE OF INDIVIDUALS $D^{2}$ RELATIONSHIPS BETWEEN SYMBOLS

AND REFERENTS FOR FEMALE SS

SUMMARY OF DISTANCES FROM SYMBOIS

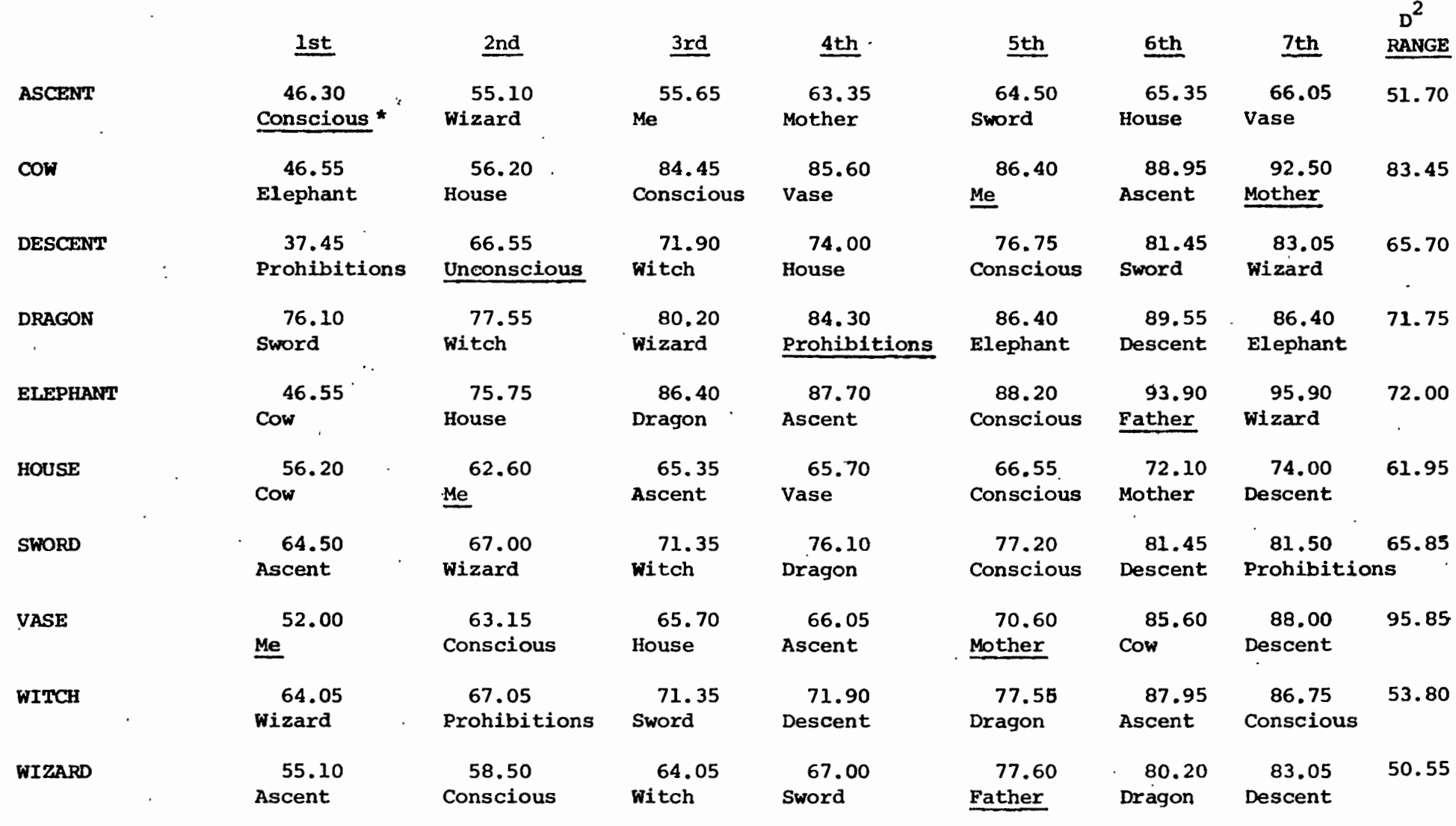

*underlined concepts represent the theoretical referent for the symbol on the left. If no concept is underlined in a given row, the theoretical referent did not appear in the first seven closest distances. 
TABLE XVIII

AVERAGE OF INDIVIDUALS ${ }^{2}$ RELATIONSHIPS BETWEEN SYMBOLS AND REFERENTS FOR THE COMBINED SAMPLE

\begin{tabular}{|c|c|c|c|c|c|c|c|c|c|c|c|c|c|c|}
\hline ASCENT & 0 & & & & & & & & & & & & . & \\
\hline CONSCIOUS & 48.32 & & & & & & & & & & & & & \\
\hline cow & 85.88 & 83.30 & & & $\cdot$ & & & & & & & & & \\
\hline DESCENT & 83.28 & 84.45 & 84.70 & & ' & & & & & & & & & \\
\hline DRAGON & 105.00 & 121.08 & 118.73 & 95.53 & & & & . & & & & & & \\
\hline ELEPHANT & 86.25 & 91.68 & 52.78 & 94.33 & 85.85 & & & . & & & & & & \\
\hline FATHER & 76.73 & 58.40 & 91.45 & 91.65 & 116.88 & 84.93 & & & & & & . & . & \\
\hline HOUSE & 62.05 & 56.28 & 59.38 & 82.78 & 126.10 & 77.75 & 65.78 & & & & & & & \\
\hline $\mathrm{ME}$ & 57.93 & 44.35 & $89.85^{\circ}$ & 88.35 & 127.53 & 96.88 & 59.85 & 57.28 & & & & & & \\
\hline MOTHER & 69.98 & 57.45 & 91.40 & 93.25 & 158.53 & 126.48 & 94.80 & 72.28 & 60.75 & & & & & \\
\hline PROHIBITIONS & 91.38 & 101.20 & 91.75 & 46.75 & 77.83 & 99.78 & 105.55 & 100.38 & 106.55 & 107.70 & & & & \\
\hline SWORD & 72.45 & 81.68 & 129.58 & $89: 23$ & 90.70 & 105.60 & 84.43 & 95.00 & 89.08 & 119.28 & 92.58 & & & \\
\hline UNCONSCIOUS & 97.88 & 117.80 & 96.50 & 64.30 & 122.33 & 108.13 & 135.85 & 101.53 & 117.60 & 126.30 & 75.00 & 114.63 & & \\
\hline VASE & 67.58 & 71.15 & 85.95 & 83.75 & 158.38 & 119.18 & 105.10 & 70.48 & 75.40 & 69.10 & 102.10 & $118.78 \quad 89.75$ & & . \\
\hline WITCH & 108.30 & 126.73 & 132.63 & 80.03 & 86.10 & 137.85 & 156.18 & 143.65 & 138.08 & 131.13 & 68.08 & $101.80 \quad 99.38$ & 126.23 & \\
\hline WIZARD & 60.82 & 61.00 & $\mathrm{CoN}^{105.75}$ & 76.80 & 87.88 & 91.63 & $\begin{array}{l}73.45 \\
7 E^{R}\end{array}$ & 84.58 & 70.90 & 97.80 & 85.25 & ${ }_{5}^{68.48} 101.50$ & 95.95 & 93.53 \\
\hline
\end{tabular}


AVERAGE OF INDTVIDUALS $D^{2}$ RELATIONSHIPS BETWEEN SYMBOLS AND REFERENTS FOR THE COMBINED SAMPIE SUMMARY OF DISTANCES FROM SYMBOLS

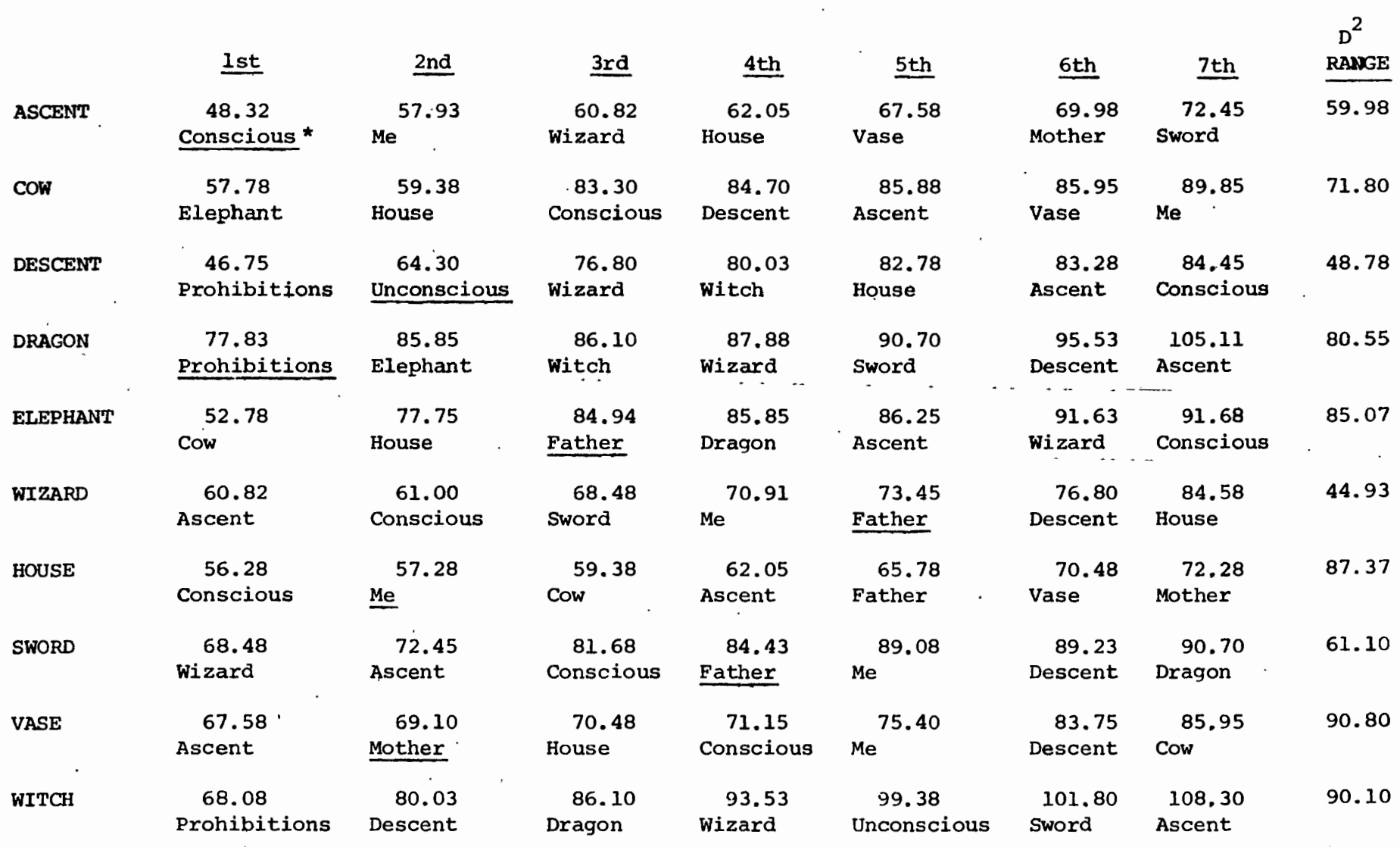

*underlined concepts represent the theoretical referent for the symbol on the left.: If ro concept is underlined in a given row, the theoretical referent did not appear in the first seven closest distances. 